\title{
Uma Estimativa dos Aspectos Distributivos da Previdência Social no Brasil*
}

\author{
Luís Eduardo Afonso** \\ Reynaldo Fernandes ${ }^{* * *}$
}

Sumário: 1. Introdução; 2. Breve revisão da literatura; 3. Metodologia; 4. Cálculo das taxas internas de retorno; 5. Conclusão.

Palavras-chave: previdência social; aspectos distributivos; idosos.

Códigos JEL: H55; J14.

Este artigo quantifica os aspectos distributivos da previdência social no Brasil, por meio do cálculo das Taxas Internas de Retorno (TIRs) proporcionadas pelas contribuições e benefícios previdenciários. Os grupos com menor nível de educação apresentam TIRs mais elevadas. As taxas também são diferenciadas conforme as regiões do país. As TIRs têm crescido ao longo do tempo. Há evidências da existência de características distributivas na previdência. Foram computados todos benefícios e contribuições, no período 1976-1999. Foram estimados os fluxos esperados de contribuições e benefícios de grupos de indivíduos representativos. Com base nestes fluxos foram calculadas as TIRs intrínsecas ao sistema previdenciário.

This paper studies the distributive aspects of the Brazilian social security system. Contributions made and received benefits for each individual were considered, in the period 1976-1999. The expected contributions and benefits flows of representative groups of individuals were then estimated. For each group, the internal rates of return inherent to the social security system were assessed. Groups with lower education levels achieve the highest rates of return. The rates are also different according to the country's regions. The rates of return have grown over the years. These results evidence the existence of distributive characteristics in the Brazilian social security system.

${ }^{*}$ Artigo recebido em mai. 2004 e aprovado em abr. 2005. Os autores agradecem os comentários e sugestões de dois pareceristas anônimos, feitos para uma versão anterior deste artigo.

${ }^{* *}$ FGV/EAESP e ESPM. E-mail: lafonso@fgvsp.br

${ }^{* * *}$ FEA-RP/USP. E-mail: refernan@usp.br 


\section{Introdução}

Nos últimos anos, de forma similar ao que ocorreu em outros países, como EUA, Inglaterra Alemanha e Argentina, a previdência social ganhou relevância na agenda político-econômica do Brasil. Tornou-se consensual a visão do equacionamento adequado da questão previdenciária como um dos pilares para a organização das contas públicas. Esta condição necessária tornou-se ainda mais cristalina após a estabilização econômica posterior ao Plano Real. O equilíbrio financeiro até então existente mostrou-se frágil, tendo se desvanecido e transformado rapidamente em crescentes déficits.

No caso do Regime Geral de Previdência Social (RGPS) do Instituto Nacional do Seguro Social (INSS), estes déficits foram influenciados pela incorporação de benefícios assistenciais, que acentuaram seu caráter distributivo, particularmente após a Constituição de 1988. No caso dos Regimes Próprios de Previdência Social (RPPS), um conjunto de regras, que deu aos servidores públicos direitos inacessíveis aos trabalhadores do setor privado, desempenhou papel igualmente relevante. $^{1}$

O consenso apontado nos parágrafos anteriores tem um aspecto primordialmente fiscalista, focando-se no equilíbrio financeiro dos sistemas previdenciários, por meio da comparação entre as receitas e despesas em cada período de tempo. No entanto, a previdência social tem um caráter essencialmente intertemporal, visto que contribuições e benefícios são efetuados em períodos diferentes da vida dos indivíduos. Desta maneira, a incorporação da dimensão temporal pode colaborar para tornar mais rica a análise de outras características da previdência, como as questões distributivas, particularmente entre gerações diferentes. ${ }^{2}$

\footnotetext{
${ }^{1}$ Os privilégios mais notáveis são o direito à integralidade (o benefício previdenciário tem o mesmo valor da última remuneração do trabalhador) e à paridade (o valor do benefício tem os mesmos reajustes reais aplicados aos vencimentos dos funcionários da ativa).

${ }^{2}$ A previdência também tem a característica de seguro social. Pessoas de renda mais baixa não teriam como realocar intertemporalmente seu fluxo de consumo, por meio de poupança, dado que os mercados privados são incompletos. Os sistemas previdenciários, por sua natureza, ajudam a minimizar esta falha. Sobre este ponto, ver Hubbard e Judd (1987).
} 
Algumas contribuições recentes ao tema têm centrado sua análise na função desempenhada pelos benefícios previdenciários. ${ }^{3}$ Embora estes obviamente tenham um papel importante na composição da renda das famílias com idosos e na redução da pobreza, tal enfoque pode não ter a abrangência necessária, visto não abarcar todos os motivos de existência e da lógica de funcionamento dos sistemas previdenciários. Ou seja, desta forma não se contabilizam todos os dispêndios e recebimentos efetuados pelas pessoas e as análises efetuadas desta forma ficam incompletas.

Como lembra Diamond (1977), para se analisar os sistemas previdenciários públicos, cuja função básica é funcionar como um seguro social, antes é necessário compreender as razões que justificam sua existência. A primeira é a ocorrência de falhas de mercado, que prejudicariam a acumulação de ativos ao longo da vida ativa. A segunda é a possibilidade de os indivíduos subpouparem, seja por miopia, como aponta Feldstein (1985), seja por racionalidade, pois sabem que sociedade lhes proporcionará meios mínimos de sobrevivência durante a velhice, conforme o argumento de Veall (1986). A terceira razão são os ganhos de eficiência que um sistema público compulsório teria em relação aos fundos privados, por não ter os custos de atração de novos segurados. Finalmente, a quarta razão, com a qual este trabalho guarda relação mais estreita, é a possibilidade de execução de políticas públicas de cunho distributivo, em termos intra e intergeracionais. Portanto, fica evidente que a previdência social pode desempenhar concomitantemente múltiplas funções, como a realocação intertemporal de recursos (a priori, atuarialmente neutra) e a distribuição de renda, obrigatoriamente não neutra.

Um sistema previdenciário cuja característica mais relevante seja a de funcionar como um seguro social pode ser designado como Bismarckiano. Um sistema que enfatize os funções distributivas, objetivando a redução da pobreza ou da desigualdade, pode ser qualificado como Beveridgeano. ${ }^{4}$ Usando-se argumento análogo àquele desenvolvido no clássico texto de Buchanan (1968), pode-se afirmar que analisar somente os gastos com benefícios corresponde a uma ênfase maior nos aspectos assistenciais, em detrimento do papel básico de seguro social.

\footnotetext{
${ }^{3}$ Ver, por exemplo, Barros e Carvalho (2003:5) que incluem a previdência nos gastos sociais, Hoffmann (2003) e Giambiagi et alii (2004).

${ }^{4}$ Os termos referem-se, respectivamente, às características dos sistema previdenciários alemão (criado por Bismarck) e inglês (sob inspiração do relatório Beveridge). Para uma visão mais detalhada, ver Conde-Ruiz e Profeta (2003). 
Dentre as outras características da previdência social, que não a de realocação intertemporal de recursos, talvez a mais instigante sejam os aspectos distributivos. Estes são inerentes a quaisquer sistemas previdenciários devido à complexa dinâmica das variáveis demográficas e econômicas e ao fato destes sistemas usualmente agregarem programas de cunho assistencial. Com o intuito de se avaliar as políticas empreendidas pelo país na área previdenciária, este processo distributivo pode ser analisado e quantificado. A forma mais habitual, padrão nos trabalhos que tratam do tema, é por meio do cálculo da taxa interna de retorno (TIR) referente à previdência social. Esta é a taxa que iguala os fluxos esperados de contribuições efetuadas e de benefícios recebidos pelos indivíduos ao longo de suas vidas.

Com base na literatura internacional sobre o assunto, segue-se uma linha até agora pouco explorada nos trabalhos nacionais. Neste artigo faz-se uma estimativa dos aspectos distributivos intra e intergeracionais da previdência brasileira, tendo como base as contribuições efetuadas e os benefícios recebidos pelos indivíduos.

Duas questões fundamentais sobre as características e as funções da previdência social brasileira são tratadas no texto. A primeira é quanto ao valor dos benefícios: serão eles de fato tão reduzidos quanto concebido usualmente? A segunda é quanto ao caráter distributivo: seria a previdência injusta com seus segurados? Ou ela pode ser um tipo de contrato social vantajoso para determinados grupos?

Visando responder a essas questões, são testadas duas hipóteses. A primeira é que o sistema previdenciário brasileiro não paga benefícios tão baixos (dadas as contribuições correspondentes) quanto se costuma apregoar. A segunda é que a existência das organizações previdenciárias pode ser vantajosa para alguns grupos, particularmente aqueles com renda mais baixa. De modo oposto, para as faixas de renda mais elevadas, os ganhos parecem ser menores. Evidências na direção dessas hipóteses confirmariam o caráter distributivo e a progressividade do sistema previdenciário brasileiro. Os resultados obtidos neste trabalho permitem que se possa quantificar o papel desempenhado pela previdência social brasileira, no tocante à distribuição intra e intergeracional de recursos.

Além da introdução, há mais quatro seções. A seguir é feita uma breve revisão da bibliografia sobre o assunto. A seção 3 traz a metodologia do artigo. São descritos a forma de agregação dos indivíduos, os dados utilizados e a técnica de cálculo de benefícios e contribuições. Na seção 4, estimam-se para cada grupo de indivíduos com determinadas características, os fluxos de contribuições e benefícios para os períodos anterior a 1976 e posterior a 1999. São então calculadas as taxas 
internas de retorno obtidas por cada grupo. Por meio destas é possível quantificar os aspectos distributivos do sistema previdenciário brasileiro. Encerrando, são apresentadas as conclusões.

\section{Breve Revisão da Literatura}

Um exame da literatura mostra que os aspectos distributivos da previdência têm duas dimensões, não excludentes entre si. A primeira é a distribuição intrageracional causada pelo sistema previdenciário. Neste caso, as TIRs de pessoas ou grupos pertencentes a uma mesma coorte, mas com características diferenciadas, são diferentes. A segunda dimensão é a distribuição intergeracional. Esta ocorre quando pessoas ou grupos de coortes distintas, nascidas em momentos diversos, têm TIRs diferentes.

Para o cálculo dos aspectos distributivos, tanto intra como intergeracionais, podem ser empregadas duas metodologias. De acordo com Leimer (1999), as diferenças entre ambas referem-se aos dados utilizados. A primeira metodologia usa dados reais, provenientes de registros da entidade previdenciária do país. Esta primeira abordagem tem a vantagem de empregar dados de segurados reais, que efetivamente contribuíram e receberam benefícios da previdência social. A desvantagem é que usualmente os órgãos previdenciários não dispõem de algumas informações necessárias, como o estado conjugal dos segurados. ${ }^{5}$

A segunda metodologia corresponde à construção de fluxos de contribuições e benefícios esperados de grupos de trabalhadores representativos ou hipotéticos, agrupados com base em características como educação e gênero. Neste caso, a divisão por grupos envolve algum grau de discricionariedade e impõe o conhecimento das regras de cálculo de contribuições e de benefícios que vigoraram ao longo dos anos.

De forma bastante sintética, pode-se dividir os trabalhos sobre o tema em duas gerações. A primeira inicia-se com Aaron (1977), que encontra evidências de que as taxas de retorno relativas ao $\mathrm{OASI}^{6}$ norte-americano vêm caindo ao longo dos anos, havendo assim distribuição intergeracional feita pelo sistema previdenciário. Seus resultados são corroborados pelos trabalhos de Leimer e Petri (1981) e Burkhauser e Warlick (1981). A incorporação da heterogeneidade intrageracional ocorre com Hurd e Shoven (1983), que são seguidos por Boskin et alii (1987), Boskin e Puffert

\footnotetext{
${ }^{5}$ Esta informação é necessária para o cálculo das pensões.

${ }^{6}$ Old Age and Survivors Insurance. Programa de aposentadorias e pensões da Social Security Administration (SSA) dos EUA.
} 
(1987), Myers e Schobel (1992) e Duggan et alii (1993). Seus resultados mostram a existência de progressividade (ou seja, distribuição intrageracional) na previdência dos EUA, dado que as taxas de retorno dos indivíduos menos educados, dos mais pobres e das mulheres é mais elevada que a dos demais grupos. A tabela 1 apresenta um resumo dos resultados principais de alguns trabalhos desta primeira geração. ${ }^{7}$

Tabela 1

Taxas internas de retorno anuais médias $-1^{a}$ geração

\begin{tabular}{ccc}
\hline Trabalho & Grupo & TIR (\% a.a.) \\
\hline Leimer e Petri (1981) & Coorte de 1917 & 6,7 \\
& Coorte de 1955 & 2,4 \\
\hline Hurd e Shoven (1983) & Homens da coorte de 1905 (renda média) & 6,3 \\
& Homens da coorte de 1945 (renda média) & 1,3 \\
& Mulheres da coorte de 1905 (renda média) & 9,1 \\
& Mulheres da coorte de 1945 (renda média) & 3,4 \\
\hline Boskin et alii (1987) & Casais da coorte de 1945 (renda média) & 2,07 \\
& Casais da coorte de 1945 (renda baixa) & 3,50 \\
& Casais da coorte de 1960 (renda média) & 1,54 \\
& Casais da coorte de 1960 (renda baixa) & 3,08 \\
\hline
\end{tabular}

Fonte: Organizado pelos autores.

Os resultados da segunda geração de trabalhos são menos conclusivos. Seu início ocorre com Garrett (1995), que incorpora de forma consistente a correlação negativa existente entre renda e taxas de mortalidade. Sua conclusão mais importante é que esta relação reduz a progressividade do OASI, alterando o padrão de resultados até então obtidos. Duggan et alii (1995) dão seqüência a esta linha e encontram resultados similares, utilizando, no entanto, dados reais e não indivíduos representativos, como Garrett. Beach e Davis (1998) que apresentam a novidade das taxas de mortalidade diferenciadas também por raça obtêm resultados similares. O mesmo padrão de resultados é encontrado por Gustman e Steinmeier (2001).

Anderson et alii (2001) encontram estabilidade nas taxas de retorno ao longo do tempo. Já Coronado et alii (2000b,a) encontram progressividade e caráter distributivo no OASI. Esta também é a conclusão de Feldstein e Liebman (2000), Liebman (2001) e de um conjunto de quatro policy papers: Bosworth et alii (1999), Bosworth e Burtless (2000), Bosworth e Burtless (2002) e Bosworth et alii (2003). A tabela 2 traz alguns dos resultados de trabalhos da segunda geração.

\footnotetext{
${ }^{7}$ Para uma apresentação mais completa dos resultados dos trabalhos, ver Afonso (2003).
} 
Tabela 2

Taxas internas de retorno anuais médias $-2^{a}$ geração

\begin{tabular}{ccc}
\hline Trabalho & Grupo & TIR (\% a.a.) \\
\hline Garrett (1995) & Coorte de 1925 $-1^{\circ}$ quintil de renda & 2,90 \\
& Coorte de $1925-2^{\circ}$ quintil de renda & 3,10 \\
& Coorte de $1925-4^{\circ}$ quartil de renda & 2,61 \\
\hline Duggan et alii (1995) & Coorte de 1917 a 1922- Homens de renda alta & 6,17 \\
& Coorte de 1917 a 1922- Homens de renda média & 5,58 \\
& Coorte de 1917 a 1922- Homens de renda baixa & 5,04 \\
\hline Anderson et alii (2001) & Coorte de 1949 & 2,34 \\
& Coorte de 1969 & 2,61 \\
& Coorte de 1989 & 2,59 \\
\hline
\end{tabular}

Fonte: Organizado pelos autores.

Os trabalhos de Gil e Lopez-Casasnovas (1997) e Sinn (1999), respectivamente, para Espanha e Alemanha, apontam para a existência de distribuição intergeracional, dada a redução nas taxas de retorno na segunda metade do século XX.

Essa também é a conclusão a que chegam Fernandes (1994) e World Bank (1995) ao estudar a previdência brasileira. Fernandes constrói um modelo teórico de previdência social, sob o regime de repartição e analisa o impacto que as mudanças na estrutura demográfica brasileira teriam sobre o equilíbrio do sistema. Em World Bank (1995) são calculadas as TIRs de diversos grupos, construindo-se para cada um deles, de acordo com as regras previdenciárias válidas em 1992 e empregando-se os dados da PNAD de 1988, as projeções de benefícios e contribuições. A tabela 3 sintetiza os resultados destes dois textos.

Neste artigo apresentamos duas contribuições em relação a estes dois textos. A primeira é a heterogeneidade intrageracional. Este ponto não é tocado pelo trabalho de Fernandes, que trabalha com um indivíduo representativo por coorte. A segunda é incorporar de forma consistente ao cálculo dos benefícios e contribuições as várias mudanças de regras por que passou o sistema previdenciário brasileiro. Fernandes (1994) usa um modelo estático de previdência social. Em World Bank (1995) é empregada apenas uma PNAD e supõe-se, indiretamente, que as regras verificadas em 1992 valeram por todo o período de vida de cada coorte. Esta hipótese não é estritamente correta. Na seção 3 e no apêndice A mostram-se as alterações na legislação previdenciária brasileira e como elas foram empregadas nos cálculos efetuados. 
Tabela 3

Taxas internas de retorno anuais médias - Brasil

\begin{tabular}{ccc}
\hline Trabalho & Grupo & TIR (\% a.a.) \\
\hline Fernandes (1994) & Homens da coorte de 1930-35. Aposentadoria aos 60 anos & 3,01 \\
& Homens da coorte de 1985-90. Aposentadoria aos 60 anos & 2,05 \\
& Mulheres da coorte de 1930-35. Aposentadoria aos 60 anos & 3,76 \\
& Mulheres da coorte de 1985-90. Aposentadoria aos 60 anos & 2,63 \\
\hline World Bank (1995) & Homens. Aposentadoria por idade & 13,29 \\
& Mulheres. Aposentadoria por idade & 17,57 \\
& Homens. Aposentadoria por tempo de serviço & 6,98 \\
& Mulheres. Aposentadoria por tempo de serviço & 9,55 \\
\hline
\end{tabular}

Fonte: Organizado pelos autores.

Uma vez definido o objeto de estudo, a quantificação dos aspectos distributivos da previdência social, e feita a revisão da literatura sobre os aspectos distributivos, o passo imediato é definir a metodologia a ser empregada. Isto é feito a seguir, na seção 3, no qual se descreve a metodologia adotada nas seções empíricas do artigo.

\section{Metodologia}

O trabalho aqui desenvolvido é similar, do ponto de vista metodológico, ao conjunto de textos qualificados como de primeira geração. Desta maneira, os indivíduos devem ser agregados em grupos com características similares, de forma a avaliar os aspectos distributivos do sistema previdenciário brasileiro. ${ }^{8}$ A quantificação destes impactos distributivos é feita por meio do cálculo das taxas de retorno para grupos representativos. A metodologia é semelhante àquela empregada por Boskin et alii (1987) e Duggan et alii (1993).

Portanto, o primeiro passo envolve a identificação de características comuns, que podem ser usadas na construção dos grupos. Para cada um desses grupos são calculados os fluxos de contribuições e recebimentos, de 1976 a 1999. O passo seguinte consiste na projeção desses fluxos por todo o ciclo de vida dos indivíduos. Finalizando, são calculadas as taxas de retorno de cada grupo.

\footnotetext{
${ }^{8} \mathrm{O}$ termo sistema previdenciário brasileiro refere-se a todas entidades ligadas à previdência social, tanto dos funcionários do setor público (por meio dos RPPS), quanto dos funcionários de setor privado, por meio do RGPS do INSS.
} 


\subsection{Divisão por grupos}

\section{Características Comuns}

A separação em grupos consiste na divisão dos indivíduos, de acordo com características comuns, que não se alterem ao longo do tempo. Ou, caso isso não seja possível, em características que apresentem pequena variação. $\mathrm{O}$ primeiro critério para a formação dos grupos é o ano de nascimento. O segundo critério é geográfico, de acordo com as regiões do país. Assim, as pessoas que nasceram no mesmo ano (pertencentes a uma mesma coorte ou geração) são divididas em quatro regiões:

- Região 1: Sul;

- Região 2: Sudeste;

- Região 3: Nordeste;

- Região 4: Norte + Centro-Oeste..$^{9}$

O terceiro critério consiste na divisão dos indivíduos conforme sua educação. Foram construídos três níveis educacionais. Propositadamente, a separação não é muito restrita, pois procurou-se evitar a existência de células com número de observações muito reduzido, dado que o número médio de anos de estudo, particularmente das coortes mais velhas, é bastante baixo. Os níveis são os seguintes:

- Nível 1: 0 a 4 anos de estudo;

- Nível 2: 5 a 8 anos de estudo;

- Nível 3: 9 ou mais anos de estudo.

Cada Grupo, de acordo com a designação a partir daqui adotada, é composto pelas pessoas que nasceram no mesmo ano, moram na mesma região e pertencem ao mesmo nível educacional. Por exemplo, o Grupo 195832, é formado por todos os que nasceram em 1958, moram na região nordeste (região 3) e pertencem ao nível 2 de educação, ou seja, têm de 5 a 8 anos de estudo.

\footnotetext{
${ }^{9}$ As regiões Norte e Centro-Oeste foram agregadas devido ao número reduzido de observações, particularmente para as coortes mais velhas, com níveis de educação mais elevados. 


\section{Contribuiç̧̃̃es e Vínculo Profissional}

O próximo passo é calcular as contribuições efetuadas por cada indivíduo, com base nas diferentes regras da previdência. É necessário separar os trabalhadores em duas categorias: empregados do setor público e do setor privado.

O conjunto de trabalhadores do setor público deve ser dividido em duas partes: aqueles cujos contratos de trabalho são regidos pela CLT (Consolidação das Leis do Trabalho) e aqueles vinculados ao RJU (Regime Jurídico Único). Para o primeiro grupo valem as mesmas condições vigentes para os trabalhadores do setor privado. Já aqueles ligados ao RJU têm uma série de direitos diferenciados, dos quais o mais relevante é a aposentadoria com salário integral. ${ }^{10}$

O conjunto de trabalhadores do setor privado foi dividido em quatro categorias, tendo como critério a existência de regras particulares de contribuição. A primeira categoria é composta pelos trabalhadores comuns. Estes são os empregados em empresas privadas não pertencentes ao setor financeiro. A segunda é formada pelos empregados em empresas do setor financeiro. Essa separação é feita porque a partir de 1987 a alíquota das empresas financeiras passou a ser 2,5 pontos percentuais maior que a alíquota dos demais setores. A terceira categoria é formada pelos trabalhadores domésticos. A última categoria é formada pelos autônomos e contaspróprias. Estes não contribuíam, no período analisado, como os trabalhadores comuns, mas sim por meio de uma intrincada escala de salários-base, com base nos anos de filiação à previdência.

Resumindo, classificaram-se os contribuintes em seis categorias, listadas a seguir.

- Empregados do setor público

Empregados com contrato de trabalho regido pela CLT;

Empregados vinculados ao RJU.

- Empregados do setor privado

Empregados comuns (trabalhadores de empresas não-pertencentes ao setor financeiro);

Empregados de empresas do setor financeiro;

- Empregados domésticos;

- Trabalhadores autônomos e contas-próprias.

${ }^{10} \mathrm{~A}$ EC 41, aprovada em 2003, eliminou o direito à aposentadoria integral para os novos servidores públicos. 


\subsection{Fonte dos dados: características e limitações}

A fonte dos dados é a Pesquisa Nacional por Amostra de Domicílios (PNAD). Foram utilizadas todas as PNADs do período 1976-1999. Os dados das PNADs não são muito detalhados quanto à previdência. As limitações referentes aos benefícios merecem algumas considerações.

A primeira limitação é a inexistência de separação entre benefícios rurais e urbanos. Um possível caminho para superar essa restrição seria considerar como beneficiários da previdência rural (urbana) todos que moram em áreas rurais (urbanas). Porém, as classificações do Ministério da Previdência Social ${ }^{11}$ (MPS) e da PNAD não são totalmente compatíveis. O MPS usa como critério o vínculo empregatício que deu origem à aposentadoria. Este é diferente da PNAD, na qual o critério é geográfico, sendo possível identificar apenas se o domicílio no qual o indivíduo mora está em uma área rural ou urbana. Porém, como apontam Silva e Delgado (2000) 54,7\% e 51,0\% dos beneficiários da previdência rural das regiões nordeste e sul, respectivamente, moravam em áreas urbanas.

A segunda limitação é a inexistência de separação entre os benefícios previdenciários típicos, como aposentadorias por tempo de contribuição e benefícios de cunho assistencial, como os auxílios e rendas mensais vitalícias. Uma terceira limitação é a impossibilidade de se conhecer o tipo de aposentadoria recebida pelo beneficiário. Pelo questionário da PNAD é possível saber o valor da aposentadoria, mas não se consegue distinguir se o indivíduo é um aposentado pelo INSS, ou do setor público.

Também não há dados sobre a data de aposentadoria, o que implica que mesmo que a PNAD fosse um painel, não seria possível conhecer com precisão (ao menos sem hipóteses adicionais) os fluxos individuais de contribuições e benefícios. Uma última restrição é o fato de não ser possível separar os grupos com base na cor ou raça, dado que esta questão consta em todas as PNADs do período 1992-1999, mas aparece somente em alguns anos das décadas de 70 e 80.

\subsection{Cálculo de contribuições e benefícios}

Os cálculos efetuados dividem-se em duas partes. Na primeira são contabilizados os valores dos três tipos de benefícios previdenciários que constam nas PNADs: aposentadorias, pensões, e abonos-permanência. A soma de seus valores deve refletir os dispêndios do INSS e os gastos efetuados com os benefícios dos funcionários públicos das três esferas de governo.

\footnotetext{
${ }^{11}$ Até o início de 2003, a denominação era Ministério da Previdência e Assistência Social (MPAS). Com a separação da área assistencial, alterou-se o nome do ministério. 
A segunda parte é mais elaborada, dado que não há nas PNADs perguntas sobre as contribuições. Assim, seus valores têm que ser inferidos indiretamente, por meio de outras respostas existentes no questionário da PNAD. Para que sejam calculadas as contribuições, é preciso dispor de um conjunto de quatro informações: o valor dos rendimentos do trabalho, a classificação funcional do indivíduo (dada pelas seis categorias anteriormente apresentadas), sua situação como contribuinte (ou não) ao sistema previdenciário e, finalmente, as regras de contribuição relativas a cada categoria para cada ano. Entende-se por regra de contribuição o seguinte conjunto de parâmetros:

- Alíquota de contribuição do trabalhador;

- Alíquota de contribuição do empregador (quando esta existir);

- Teto de contribuição (quando este existir) para empregadores e trabalhadores.

As três primeiras informações provêm diretamente das PNADs. Já as regras de contribuição foram obtidas por outros meios e devem ser compatibilizadas com os dados das PNADs. A fonte primária para obtenção destas regras, para o RGPS do INSS, foi o Suplemento Histórico do Anuário Estatístico do MPAS - 1999 (MPAS, 1999a). De forma complementar, para o conhecimento da legislação específica, utilizou-se como fonte básica de informações a Base Referencial da Legislação Federal do Brasil, disponibilizada no site www.planalto.gov.br, do governo brasileiro. As mudanças nas regras de contribuição ocorridas no período 1976-1999 estão listadas no apêndice A.

Como os dados da PNAD são relativos apenas ao mês de setembro, é preciso encontrar um critério de anualização. A solução imediata seria multiplicar os valores por 13, levando em conta os 12 meses do ano, mais um mês adicional, devido ao $13^{\circ}$ salário. Porém, o mês de setembro pode não ser uma proxy adequada para tal cálculo. Assim, decidiu-se usar como parâmetro os dados do MPAS referentes à parcela representada pela arrecadação do mês de setembro em relação ao total do ano. Tais dados foram obtidos apenas para os anos de 1996 a $1999 .{ }^{12}$ Para os demais anos, não existindo informação mais precisa, supôs-se que os valores de setembro representam $1 / 13$ do ano.

Um segundo ponto refere-se às mudanças nas regras de contribuição. As regras válidas para setembro (mês da PNAD) poderiam não se constituir em uma representação adequada da legislação vigente durante o ano todo. Visando contornar

\footnotetext{
${ }^{12}$ Ver anuário MPAS 1998-1999, capítulo 33, planilha 33.1.
} 
esse possível problema, resolveu-se, para cada ano em que houvesse mudança nas regras, construir um mês de setembro sintético. ${ }^{13}$

Isto é feito por meio da ponderação das regras, com base no seu período de vigência. Exemplificando: suponha-se que em um ano houve uma mudança na legislação para uma determinada categoria e duas regras vigoraram. A primeira (Regra 1) por 5 meses e a segunda (Regra 2) por 7 meses. Então a regra de setembro sintética é dada por:

$$
\text { Regra de Setembro }=\frac{5}{12} \text { Regra } 1+\frac{7}{12} \text { Regra } 2
$$

O procedimento descrito acima foi feito para todas as categorias de trabalhadores, em todos os anos da amostra. Com base na metodologia descrita, neste exemplo calculam-se as contribuições de acordo com as Regras 1 e 2. Os valores encontrados foram ponderados, encontrando-se o valor de acordo com a Regra de Setembro. Os valores das contribuições foram então anualizados, de acordo com o procedimento descrito anteriormente. Aplicando-se a Regra de Setembro a cada indivíduo e somando-se as variáveis devidas, tem-se a cada ano o total de contribuintes e o valor de suas contribuições.

É necessário calcular as contribuições dos empregadores e dos contas-próprias. Sua alíquota é diferenciada, com base em um número de classes (função de múltiplos de um determinado salário de referência), nas quais o trabalhador deve manter-se por um número mínimo de meses. ${ }^{14}$ Com as informações das PNADs, não é possível determinar-se a alíquota paga por cada empregador ou contaprópria, dado que não se conhece o período de contribuição e o período de permanência na classe atual.

Dada esta restrição, optou-se por calcular endogenamente esta alíquota. Com base nos dados agregados do MPAS ${ }^{15}$, foi calculada a parcela que as contribuições dos contribuintes individuais (como são classificados os autônomos e contas-próprias pelo MPAS) representam em relação ao montante total de contribuições de empresas e assalariados. Com esta fração, calculou-se uma alíquota de contribuição endógena para os contas-próprias e autônomos, de maneira que, utilizando-se os

\footnotetext{
${ }^{13}$ Mudanças de regras de contribuição foram freqüentes no sistema previdenciário brasileiro, particularmente na década de 80. Por este motivo, procurou-se encontrar uma forma de incorporar estas alterações nos cálculos, para todas as categorias de trabalhadores, por meio da metodologia descrita.

${ }^{14}$ Há alguns anos, o número de classes vem sendo reduzido. O objetivo é ampliar o número de autônomos contribuintes e uniformizar as regras de contribuição, tornando-as iguais às regras dos contribuintes comuns. Ver MPAS (1999b).

${ }^{15}$ Ver anuário MPAS 1998-1999, capítulo 25.
} 
dados da PNAD, a parcela das contribuições desse grupo em relação ao total representasse a mesma fração para os dados agregados dos contribuintes do setor privado. Foi possível calcular a fração das contribuições de contas-próprias e autônomos apenas para o período 1986-1999. Para o período 1976-1985, as informações necessárias não são disponibilizadas pelo MPAS. Na ausência destes dados, resolveu-se utilizar como proxy desta alíquota endógena a média calculada para o período 1986-1999.

A quarta hipótese refere-se às regras de contribuição dos funcionários públicos. Este talvez seja o grupo mais problemático, dada a quantidade (pequena) e a qualidade (baixa) das informações. Considerou-se que os estatutários, militares e funcionários sem carteira do setor público contribuem à previdência com alíquota de $11 \%$. De forma oposta, considerou-se que o empregador (União, estados ou municípios) não contribui à previdência.

As regras de contribuição são aplicadas aos indivíduos das seis categorias, com rendimentos do trabalho positivos e que declaram contribuir à previdência. Àqueles que não contribuem, é imputado zero como valor de contribuição. Todos os valores monetários foram transformados em valores de setembro de 1999. Para isto foi empregada a série mensal do INPC do IBGE, até abril de 1979. Para períodos anteriores, foi utilizada a série mensal do IPC/RJ, calculado pela FGV/RJ.

Resta tratar das pensões. A probabilidade de um homem receber uma pensão referente a sua esposa é bastante reduzida, principalmente nos anos iniciais da amostra. Isto ocorre devido à maior expectativa de vida feminina e à menor inserção da mulher no mercado de trabalho, particularmente para as coortes mais velhas. É razoável supor que todas as pensões são recebidas por mulheres. O fluxo de benefícios de cada pensão está descolado, em termos individuais, do fluxo de contribuições que lhe deu origem. Pode-se tratar as pensões como uma extensão dos benefícios a que o marido (em nosso caso, o Grupo a qual ele pertencia) teria direito. Deve-se repartir as pensões, dentro de cada Grupo, para os homens cujos fluxos de contribuições (e posteriores aposentadorias) deram origem às pensões. 
Foi feita uma divisão dos indivíduos por nível de educação, região e classe de idade. Foram geradas treze classes de idade, em faixas de 5 anos, com exceção da primeira que engloba todos indivíduos com idade igual ou inferior a 29 anos e o último, que abarca todos aqueles com mais de 79 anos. ${ }^{16}$ Foi então somado o valor das pensões recebidas pelas mulheres pensionistas de cada grupo. Dividiuse o valor das pensões pelo número de homens em cada grupo. Finalizando o procedimento, os valores oriundos dessa divisão foram somados aos benefícios previdenciários recebidos pelos homens de cada Grupo.

Com base nas seis categorias de trabalhadores e no histórico das regras de contribuição foram computados a cada ano, para todos os indivíduos, os valores de contribuição, anualizando-os conforme o procedimento descrito anteriormente. Aos valores das aposentadorias foram incorporados os valores das pensões. Os valores de benefícios e contribuições foram então expandidos, com base no peso de cada indivíduo no total da população. Finalizando, estes valores foram somados por Grupo. Assim, temos a cada ano do período 1976-1999, as contribuições efetuadas e os benefícios recebidos para cada Grupo.

\subsection{Uma sucinta descrição dos dados}

Há um rápido envelhecimento da população, cuja idade média passa de 23,96 anos em 1976 para 28,70 anos em 1999. Um reflexo desse fato e da expansão do sistema previdenciário é a expansão no número de beneficiários, que passou de cerca de 4,7 milhões para 18,5 milhões, configurando uma taxa anual de crescimento de $6,1 \%$ de 1976 a 1999 . No mesmo período, o número de pensionistas cresceu $6,4 \%$ ao ano. Em contrapartida, o número de contribuintes à previdência cresceu a uma taxa bastante inferior (2,3\%), aumentando de 18,2 milhões para 31,0 milhões. Estes fatos podem ser visualizados na figura 1.

\footnotetext{
${ }^{16} \mathrm{~A}$ divisão feita teve como critério gerar classes que não fossem nem muito grandes (e assim formassem grupos muito heterogêneos), nem reduzidas demais (o que geraria células com número reduzido de observações). Após algumas tentativas, a divisão por períodos de 5 anos, foi a que pareceu atender melhor a esses dois critérios.
} 
O crescimento dos dispêndios com benefícios a uma taxa bastante superior ao crescimento das contribuições tende a gerar desequilíbrios entre receitas e despesas do sistema previdenciário. Uma das formas para tentar equacionar esse desequilíbrio foi o contínuo aumento das alíquotas efetivas de contribuição dos trabalhadores comuns, que passaram de 21,80\% em 1976 para 26,91\% em 1999 . Estas alíquotas foram calculadas dividindo-se a contribuição relativa a todos estes indivíduos (considerando-se a parcela do trabalhador e da empresa) pela soma das suas remunerações.

Figura 1

Número de aposentados, pensionistas, beneficiários e contribuintes do sistema previdenciário (1976-1999)

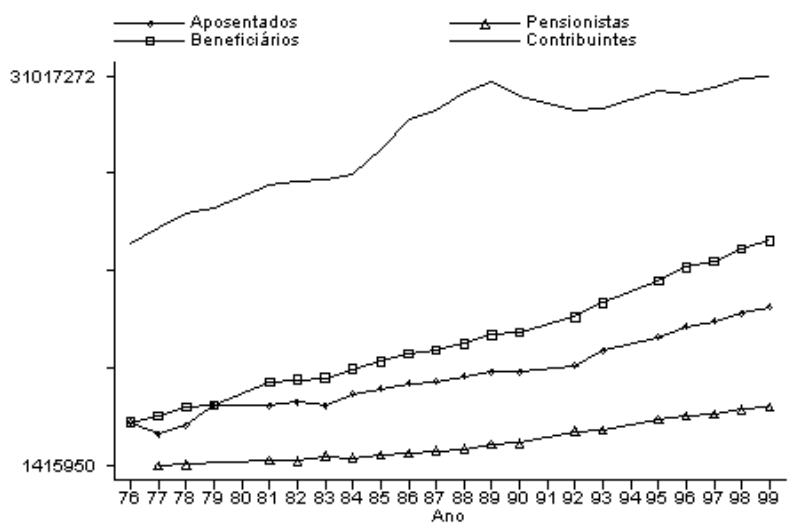

Em valores reais, em 1976 as contribuições somavam $\mathrm{R} \$ 25,7$ bilhões, valor que chegou a $\mathrm{R} \$ 51,1$ bilhões em 1999. No mesmo período, os gastos com benefícios passaram de $\mathrm{R} \$ 19$ bilhões para mais de $\mathrm{R} \$ 94$ bilhões, o que representa uma taxa anual de crescimento superior a $7,2 \%$. Estes dados, assim como os valores das aposentadorias e pensões estão representados na figura 2. O aumento dos dispêndios com benefícios tem três razões principais. A primeira é a elevação na proporção de pessoas idosas (com idade superior a 60 anos) que era de $5,95 \%$ da população em 1976 e atinge 8,63\% em 1999. A segunda é o aumento na porcentagem de idosos beneficiários, que passa de 46,37\% em 1976 para 77,29\% em 1999, como pode ser visto na tabela 4. A terceira razão é o aumento real dos valores das aposentadorias. A aposentadoria média real em 1976 era de $\mathrm{R} \$$ 310,97. Após muitas oscilações no final dos anos 80, esse valor atinge $\mathrm{R} \$$ 405,76 em 1999. 


\section{Figura 2}

Benefícios e contribuições ao sistema previdenciário (1976-1999) (valores em $\mathrm{R} \$$ bilhões de setembro/99)

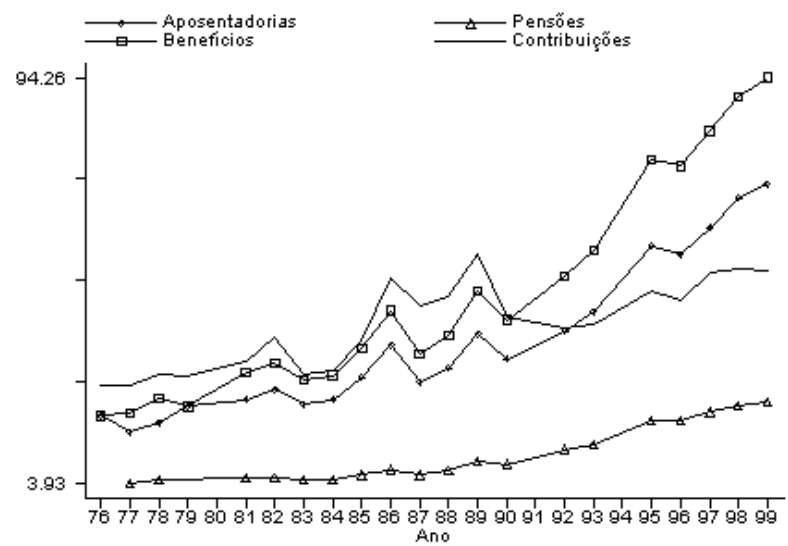

Tabela 4

Características das pessoas idosas (1976-1999)

\begin{tabular}{ccc}
\hline Ano & $\begin{array}{c}\text { Idosos em relação } \\
\text { ao total da população (\%) }\end{array}$ & $\begin{array}{c}\text { Idosos beneficiários } \\
\text { da previdência (\%) }\end{array}$ \\
\hline 1976 & 5,95 & 46,37 \\
1977 & 5,94 & 49,05 \\
1978 & 6,00 & 54,57 \\
1979 & 6,20 & 54,75 \\
1981 & 6,02 & 59,76 \\
1982 & 5,98 & 60,57 \\
1983 & 6,12 & 59,75 \\
1984 & 6,40 & 62,32 \\
1985 & 6,43 & 63,82 \\
1986 & 6,59 & 64,66 \\
1987 & 6,64 & 64,97 \\
1988 & 6,82 & 65,26 \\
1989 & 7,01 & 65,81 \\
1990 & 7,27 & 67,26 \\
1992 & 7,54 & 69,09 \\
1993 & 7,61 & 73,52 \\
1995 & 7,92 & 76,28 \\
1996 & 8,22 & 76,30 \\
1997 & 8,22 & 76,15 \\
1998 & 8,40 & 76,67 \\
1999 & 8,63 & 77,29 \\
\hline Fonte: PNADs 1976-1999. Tabulações dos autores.
\end{tabular}


Finalizando as estatísticas descritivas, as tabelas 5 e 6 apresentam os valores das contribuições e benefícios previdenciários no período 1976-1999, agregados por região e nível de educação, conforme o critério adotado na divisão dos Grupos.

Tabela 5

Benefícios por Grupo (1976-1999)

(valores em $\mathrm{R} \$$ bilhões de setembro/99)

\begin{tabular}{|c|c|c|c|c|c|c|c|c|c|c|c|c|}
\hline \multicolumn{13}{|c|}{ Região e nível de educação } \\
\hline \multirow[b]{2}{*}{ Ano } & \multicolumn{3}{|c|}{ Sul } & \multicolumn{3}{|c|}{ Sudeste } & \multirow{2}{*}{\multicolumn{3}{|c|}{$\begin{array}{c}\text { Nordeste } \\
\text { Nível } 1 \text { Nível } 2 \text { I }\end{array}$}} & \multicolumn{3}{|c|}{ Norte + Centro-Oeste } \\
\hline & Nível & Nível & 2 Nível 3 & Nível 1 & Nível & Nível 3 & & & & Nível & Níve & Nível 3 \\
\hline 1976 & 1,44 & 0,79 & 0,59 & 6,34 & 2,55 & 3,85 & 1,81 & 0,52 & 0,45 & 0,38 & 0,14 & 0,15 \\
\hline 1977 & 1,77 & 0,98 & 0,66 & 6,21 & 2,28 & 3,53 & 2,07 & 0,50 & 0,52 & 0,34 & 0,12 & 0,15 \\
\hline 1978 & 1,72 & 0,95 & 0,76 & 7,20 & 2,91 & 4,10 & 2,43 & 0,55 & 0,48 & 0,47 & 0,26 & 0,27 \\
\hline 1979 & 2,09 & 0,42 & 0,67 & 7,52 & 2,09 & 3,94 & 2,50 & 0,28 & 0,57 & 0,54 & 0,12 & 0,28 \\
\hline 1980 & 2,37 & 0,59 & 1,02 & 8,45 & 2,53 & 4,86 & 2,96 & 0,42 & 0,86 & 0,75 & 0,18 & 0,44 \\
\hline 1981 & 2,61 & 0,64 & 1,13 & 9,22 & 2,71 & 5,25 & 3,34 & 0,42 & 0,91 & 0,92 & 0,19 & 0,44 \\
\hline 1982 & 2,88 & 0,71 & 1,19 & 9,83 & 2,81 & 6,12 & 3,34 & 0,51 & 0,99 & 0,87 & 0,26 & 0,49 \\
\hline 1983 & 2,45 & 0,57 & 1,15 & 8,35 & 2,63 & 5,74 & 2,80 & 0,48 & 1,05 & 0,71 & 0,18 & 0,40 \\
\hline 1984 & 2,46 & 0,65 & 1,32 & 8,93 & 2,48 & 5,69 & 3,00 & 0,40 & 0,95 & 0,79 & 0,23 & 0,49 \\
\hline 1985 & 2,84 & 0,78 & 1,63 & 10,19 & 2,92 & 7,65 & 3,58 & 0,55 & 1,23 & 0,99 & 0,28 & 0,79 \\
\hline 1986 & 3,51 & 0,79 & 2,09 & 12,46 & 3,80 & 10,15 & 4,16 & 0,57 & 1,71 & 1,19 & 0,27 & 1,05 \\
\hline 1987 & 2,45 & 0,55 & 1,74 & 8,92 & 3,07 & 8,21 & 3,10 & 0,47 & 1,75 & 0,82 & 0,26 & 0,89 \\
\hline 1988 & 2,85 & 0,81 & 1,97 & 9,48 & 3,33 & 9,71 & 3,67 & 0,62 & 1,69 & 0,98 & 0,28 & 0,99 \\
\hline 1989 & 3,42 & 0,94 & 2,48 & 13,11 & 4,20 & 11,97 & 4,33 & 0,69 & 2,00 & 1,27 & 0,38 & 1,30 \\
\hline 1990 & 2,69 & 0,81 & 2,58 & 10,39 & 3,47 & 9,91 & 3,63 & 0,72 & 2,52 & 1,22 & 0,39 & 1,54 \\
\hline 1991 & 3,60 & 0,93 & 2,47 & 11,98 & 3,66 & 10,10 & 5,25 & 0,89 & 2,50 & 1,37 & 0,42 & 1,46 \\
\hline 1992 & 4,50 & 0,98 & 2,35 & 13,57 & 3,82 & 10,30 & 6,87 & 1,02 & 2,50 & 1,52 & 0,44 & 1,36 \\
\hline 1993 & 4,94 & 1,18 & 2,93 & 14,61 & 4,32 & 11,45 & 7,33 & 0,95 & 3,03 & 1,89 & 0,51 & 1,53 \\
\hline 1994 & 5,42 & 1,36 & 3,67 & 16,00 & 5,01 & 14,66 & 8,19 & 1,28 & 4,22 & 2,18 & 0,59 & 2,21 \\
\hline 1995 & 5,88 & 1,52 & 4,40 & 17,31 & 5,65 & 17,82 & 8,97 & 1,55 & 5,40 & 2,46 & 0,65 & 2,88 \\
\hline 1996 & 5,68 & 1,64 & 4,95 & 16,60 & 6,48 & 17,40 & 8,06 & 1,53 & 4,76 & 2,11 & 0,80 & 2,79 \\
\hline 1997 & 6,05 & 1,59 & 5,43 & 18,67 & 6,92 & 20,14 & 8,27 & 1,44 & 5,83 & 2,32 & 0,85 & 3,22 \\
\hline 1998 & 6,71 & 2,10 & 6,23 & 19,64 & 8,00 & 21,75 & 9,03 & 1,65 & 6,31 & 2,50 & 0,95 & 3,81 \\
\hline 1999 & 6,77 & 2,06 & 6,50 & 20,49 & 7,46 & 23,76 & 9,41 & 1,85 & 6,33 & 2,77 & 0,93 & 4,11 \\
\hline
\end{tabular}

Fonte: Cálculos dos autores. 
Tabela 6

Contribuições por Grupo (1976-1999)

(Valores em $\mathrm{R} \$$ bilhões de setembro/99)

\begin{tabular}{|c|c|c|c|c|c|c|c|c|c|c|c|c|}
\hline \multicolumn{13}{|c|}{ Região e nível de educação } \\
\hline \multirow[b]{2}{*}{ Ano } & \multicolumn{3}{|c|}{ Sul } & \multicolumn{3}{|c|}{ Sudeste } & \multicolumn{3}{|c|}{ Nordeste } & \multicolumn{3}{|c|}{ Norte + Centro-Oeste } \\
\hline & Nível & 1 Nível & 2 Nível 3 & Nível & 1 Níve & Nível 3 & Nível & 1 Nível & 2 Nível 3 & Níve & Níve & Nível 3 \\
\hline 1976 & 1,20 & 1,04 & 1,59 & 6,20 & 3,74 & 7,32 & 0,88 & 0,63 & 1,44 & 0,44 & 0,36 & 0,86 \\
\hline 1977 & 1,45 & 1,22 & 1,64 & 6,18 & 3,53 & 7,38 & 0,93 & 0,59 & 1,23 & 0,40 & 0,33 & 0,78 \\
\hline 1978 & 1,22 & 1,13 & 1,69 & 6,42 & 3,96 & 8,53 & 1,02 & 0,59 & 1,40 & 0,51 & 0,42 & 1,06 \\
\hline 1979 & 1,45 & 0,77 & 1,69 & 6,58 & 3,44 & 8,66 & 1,12 & 0,43 & 1,61 & 0,54 & 0,36 & 1,09 \\
\hline 1980 & 1,60 & 0,87 & 2,68 & 6,57 & 3,63 & 11,81 & 1,19 & 0,51 & 2,34 & 0,60 & 0,40 & 1,68 \\
\hline 1981 & 1,75 & 0,90 & 2,06 & 6,58 & 3,62 & 9,81 & 1,27 & 0,52 & 2,08 & 0,67 & 0,39 & 1,41 \\
\hline 1982 & 1,98 & 1,08 & 2,73 & 7,30 & 4,33 & 11,72 & 1,35 & 0,60 & 2,42 & 0,76 & 0,51 & 1,81 \\
\hline 1983 & 1,47 & 0,80 & 2,05 & 5,22 & 3,19 & 9,35 & 1,00 & 0,48 & 2,02 & 0,57 & 0,38 & 1,51 \\
\hline 1984 & 1,47 & 0,85 & 2,29 & 5,08 & 3,31 & 9,62 & 0,99 & 0,44 & 2,19 & 0,58 & 0,42 & 1,65 \\
\hline 1985 & 1,72 & 1,04 & 2,84 & 6,09 & 4,05 & 12,12 & 1,19 & 0,59 & 2,69 & 0,74 & 0,56 & 2,19 \\
\hline 1986 & 2,50 & 1,52 & 3,90 & 8,71 & 5,95 & 16,37 & 1,58 & 0,80 & 3,50 & 1,10 & 0,77 & 2,84 \\
\hline 1987 & 1,90 & 1,32 & 3,64 & 7,00 & 4,93 & 15,32 & 1,30 & 0,66 & 3,39 & 0,80 & 0,63 & 2,68 \\
\hline 1988 & 1,85 & 1,20 & 3,76 & 7,03 & 5,26 & 16,72 & 1,29 & 0,69 & 3,51 & 0,76 & 0,63 & 2,92 \\
\hline 1989 & 2,18 & 1,66 & 4,84 & 8,01 & 6,60 & 20,17 & 1,35 & 0,77 & 4,02 & 0,89 & 0,74 & 3,74 \\
\hline 1990 & 1,77 & 1,31 & 3,54 & 6,18 & 4,70 & 14,21 & 1,11 & 0,64 & 3,29 & 0,79 & 0,71 & 2,78 \\
\hline 1991 & 1,77 & 1,40 & 3,52 & 6,00 & 4,88 & 13,78 & 1,07 & 0,65 & 2,98 & 0,69 & 0,65 & 2,31 \\
\hline 1992 & 1,78 & 1,51 & 3,51 & 5,83 & 5,07 & 13,37 & 1,04 & 0,68 & 2,68 & 0,60 & 0,60 & 1,86 \\
\hline 1993 & 1,80 & 1,56 & 3,59 & 5,43 & 4,85 & 14,12 & 0,93 & 0,59 & 3,12 & 0,64 & 0,62 & 2,18 \\
\hline 1994 & 1,90 & 1,69 & 4,04 & 5,79 & 5,67 & 15,44 & 1,05 & 0,70 & 3,18 & 0,69 & 0,68 & 2,28 \\
\hline 1995 & 2,00 & 1,83 & 4,52 & 6,15 & 6,51 & 16,79 & 1,17 & 0,80 & 3,24 & 0,75 & 0,73 & 2,37 \\
\hline 1996 & 1,69 & 1,77 & 4,35 & 5,43 & 6,23 & 16,45 & 1,00 & 0,84 & 3,12 & 0,70 & 0,72 & 2,36 \\
\hline 1997 & 1,86 & 1,93 & 5,09 & 5,45 & 6,37 & 19,68 & 1,07 & 0,87 & 3,97 & 0,71 & 0,86 & 3,17 \\
\hline 1998 & 1,75 & 1,95 & 5,26 & 4,96 & 6,03 & 20,53 & 1,02 & 0,88 & 4,30 & 0,75 & 0,89 & 3,44 \\
\hline 1999 & 1,57 & 1,88 & 5,68 & 4,57 & 5,74 & 20,23 & 0,97 & 0,89 & 4,43 & 0,71 & 0,81 & 3,60 \\
\hline
\end{tabular}

\section{Cálculo das taxas internas de retorno}

Nas seção 3 foi construído um banco de dados inicial com os valores referentes às PNADs do período 1976-1999. Com base neste conjunto de dados inicial, nesta seção são construídas, para cada Grupo, as trajetórias esperadas das contribuições efetuadas e dos benefícios recebidos ao longo da vida. Uma vez completada esta tarefa, pode-se calcular o valor presente líqüido dos benefícios de cada Grupo, definido como o valor presente da diferença entre benefícios recebidos e contribuições pagas. Também é possível, calcular-se a taxa interna de retorno (TIR) obtida por cada Grupo. Com base nestes resultados é possível quantificar-se os aspectos distributivos do sistema previdenciário brasileiro, em termos inter e intrageracionais. 


\subsection{Estimações}

Para estimar os fluxos de contribuições e benefícios, é necessário complementar as informações até agora disponíveis, de forma a mapear todo o ciclo de vida de cada indivíduo representativo (ou Grupo, conforme a designação adotada). O primeiro passo é imputar os valores das variáveis relevantes para os três anos (1980, 1991 e 1994) em que não há PNADs. Foi adotado um método simples, utilizando-se como proxy destes valores as médias aritméticas dos valores dos anos imediatamente posterior e anterior.

O segundo passo consiste na expansão dos valores, para os anos fora da amostra, isto é, os períodos anterior a 1976 e posterior a 1999. Esta tarefa é necessária para o cálculo das taxas de retorno e dos valores presentes, efetuado posteriormente. Os 24 anos de PNADs (já completando-se as lacunas internas) fornecem um conjunto de informações relativamente reduzido frente ao ciclo de vida dos indivíduos. É necessário estimar, por meio de procedimentos econométricos, as contribuições e benefícios que seriam observadas para cada Grupo caso houvesse PNADs disponíveis para os anos passados e futuros.

A trajetória completa das contribuições e benefícios ao longo da vida foi construída para todos os grupos, "colando-se" as previsões feitas para o período fora da amostra (períodos anterior a 1976 e posterior a 1999) ao período amostral. Ou seja, foram imputadas as variáveis relativas ao pedaço censurado das observações, com base nos anos para os quais as informações estão disponíveis. Para procederse às estimações, optou-se por uma forma simplificada do procedimento descrito, por exemplo, em Menezes-Filho et alii (2000) e Gosling et alii (1999). Foram empregadas as seguintes formas funcionais nas regressões:

$$
\ln (\text { Benefício })=\alpha_{0}+\alpha_{1} \ln (\text { coorte })+\alpha_{2} \text { idade }+\alpha_{3} \text { idade }^{2}+\sum \beta_{i} \text { dummies }
$$

$\ln ($ Contribuição $)=\alpha_{0}+\alpha_{1} \ln ($ coorte $)+\alpha_{2}$ idade $+\alpha_{3}$ idade $^{2}+\sum \beta_{i}$ dummies

De forma consistente com a divisão por Grupos, nas regressões foram utilizadas dummies de nível de educação e de região. Ou seja, a hipótese implícita é que há diferenças nos benefícios e contribuições de acordo com a educação e as regiões do país. Dada esta abordagem, deixaram-se de lado as dummies relativas à região 2 (sudeste) e ao nível de educação 3. Portanto, cada regressão tem um conjunto de cinco dummies. 
Optou-se por dividir a estimação em duas partes. A primeira, referente aos anos após 1999 e a segunda, para os anos antes de 1976. Foram feitas duas regressões para os benefícios e duas para as contribuições, cada uma referente a um dos períodos descritos acima. Adotou-se esta estratégia com base no comportamento das séries de contribuições e benefícios. No período 1976-99 várias modificações ocorreram no sistema previdenciário. Houve grande expansão no número e no valor médio dos benefícios, principalmente após 1988. Estas devem ser situações particulares, que não voltarão a se repetir. Do lado das contribuições, ocorre um fenômeno análogo. Desde 1976, as alíquotas de contribuição sofreram expressivos aumentos. Parece improvável que incremento similar se repita, dadas as resistências da sociedade e uma percepção de que se pode estar do lado direito da curva de Laffer, no qual aumentos nas alíquotas reduziriam a arrecadação previdenciária.

\subsection{Resultados}

Para a previsão dos anos posteriores a 1999 foram empregados somente os dados do período 1997-1999, tanto para as contribuições, quanto para os benefícios. Procedimento similar foi adotado para o período anterior a 1976, no qual foram utilizados os dados referentes aos anos de 1976 a 1985. Adicionalmente, foi feito também um corte por idade e por ano de nascimento. ${ }^{17}$ Os resultados das quatro regressões escolhidas são apresentados nas tabelas 7 e 8.

\footnotetext{
${ }^{17}$ Para os benefícios, somente foram empregados os registros das pessoas com mais de 30 anos, nascidas a partir de 1909 (período anterior a 1976) e 1930 (período posterior a 1999). Para as contribuições, foram usados os dados das pessoas com mais de 17 anos, nascidas a partir de 1915 (período posterior a 1999) e 1900 (período anterior a 1976).
} 
Tabela 7

Estimações de benefícios e contribuições (após 1999)

\begin{tabular}{lcc}
\hline & \multicolumn{2}{c}{ Variável dependente } \\
& $\ln$ (Benefício) & $\ln$ (Contribuição) \\
\hline ln (Coorte) & 96,79977 & 89,90532 \\
& $(-3,37)$ & $(-2,42)$ \\
Idade & 0,3499224 & 0,2697555 \\
& $(-18,6)$ & $(-13,89)$ \\
Idade2 & $-0,0023507$ & $-0,0032016$ \\
& $(-20,11)$ & $(-57,43)$ \\
Dummy Região sul & $-1,20791$ & $-1,36009$ \\
& $(-35,61)$ & $(-31,24)$ \\
Dummy Região nordeste & $-1,169851$ & $-1,757221$ \\
& $(-34,49)$ & $(-40,24)$ \\
Dummy Região norte+centro-oeste & $-1,916716$ & $-1,929442$ \\
& $(-56,50)$ & $(-43,67)$ \\
Dummy Nível de educação 1 & $-0,456905$ & $-1,038603$ \\
& $(-15,55)$ & $(-27,57)$ \\
Dummy Nível de educação 2 & $-1,217416$ & $-1,40158$ \\
& $(-41,44)$ & $(-36,27)$ \\
Constante & $-724,9023$ & $-666,9367$ \\
& $(-3,32)$ & $(-2,36)$ \\
\hline N & 1332 & 2111 \\
R2 ajustado & 0,8751 & 0,8723 \\
\hline
\end{tabular}

Obs: regressões estimadas por MQO. Estatística $t$ entre parênteses

Tabela 8

Estimações de benefícios e contribuições (antes de 1976)

\begin{tabular}{lcc}
\hline & \multicolumn{2}{c}{ Variável dependente } \\
& $\ln$ (Benefício) & $\ln$ (Contribuição) \\
\hline ln (Coorte) & 120,8017 & 85,87763 \\
Idade & $(-19,76)$ & $(-18,15)$ \\
& 0,4134916 & 0,226582 \\
Idade2 & $(-52,67)$ & $(-62,08)$ \\
& $-0,0028845$ & $-0,0028922$ \\
Dummy Região sul & $(-43,90)$ & $(-104,38)$ \\
& $-1,458443$ & $-1,556377$ \\
Dummy Região nordeste & $(-57,85)$ & $(-71,73)$ \\
& $-1,634489$ & $-1,68284$ \\
Dummy Região norte+centro-oeste & $(-64,89)$ & $(-77,76)$ \\
& $-2,554079$ & $-2,217636$ \\
Dummy Nível de educação 1 & $(-101,54)$ & $(-102,13)$ \\
& 0,8747478 & $-0,2123252$ \\
Dummy Nível de educação 2 & $(-40,06)$ & $(-11,39)$ \\
& $-0,4499098$ & $-1,024273$ \\
Constante & $(-20,6)$ & $(-53,36)$ \\
& $-909,1506$ & $-635,2637$ \\
N & $(-19,58)$ & $(-17,68)$ \\
\hline
\end{tabular}

Obs: regressões estimadas por MQO. Estatística $t$ entre parênteses 
Os resultados mostram que tanto benefícios e contribuições crescem, em relação à idade, até atingir seu ponto de máximo, dado que o sinal do coeficiente do termo quadrático é negativo. Para as contribuições, isto representa o fato esperado de as pessoas deixarem progressivamente o mercado de trabalho, diminuindo assim a massa de valores pagos à previdência por cada coorte. Para os benefícios, os valores encontrados estão captando a característica de cada coorte diminuir de tamanho, dado que seus componentes, também de forma esperada, morrem, o que reduz o montante de benefícios recebidos.

Nas regressões foram omitidas as dummies relativas à região sudeste e ao terceiro nível de educação. Os resultados mostram que os coeficientes de todas dummies das demais regiões têm sinal negativo. Isto é, o fato de um indivíduo morar em uma dessas regiões reduz os benefícios e contribuições médios, em relação à região sudeste. Com relação às dummies dos níveis educacionais, os resultados são similares, com exceção do primeiro nível, para a regressão referente ao período anterior a 1976 .

A partir das previsões geradas pelas regressões, para cada Grupo foram imputados os valores de contribuições e benefícios ao longo de seu ciclo de vida. Com base nestes valores, para cada Grupo foi calculado, a cada ano, o Valor dos Benefícios Líqüidos (VBL), dado por:

$$
V B L_{i j}=\text { Benefícios }_{i j}-\text { Contribuições }_{i j}
$$

em que $i$ é o Grupo e $j$ o ano em que os benefícios são recebidos e as contribuições são efetuadas.

O passo seguinte, efetuado de forma similar ao padrão definido pela literatura internacional, foi o cálculo das taxas internas de retorno $r$ (TIR) referentes às contribuições e benefícios de cada Grupo. ${ }^{18}$ Ou seja, foi encontrada a taxa que igualasse o valor presente dos fluxos de pagamentos e recebimentos esperados, por Grupo, ${ }^{19}$ conforme mostrado pela equação

$$
0=\sum_{k=0}^{100} \frac{\text { Benefícios }_{i k}}{(l+r)^{k}}-\sum_{k=0}^{100} \frac{\text { Contribuições }_{i k}}{(l+r)^{k}}
$$

em que, empregando-se a mesma notação definida anteriormente, $k$ é a idade dos indivíduos do Grupo. Foram calculadas as TIRs de todas coortes nascidas entre

\footnotetext{
${ }^{18}$ Utilizou-se a rotina finirr.ado, desenvolvida por Vince Wiggins e disponibilizada em www.stata.com/users/vwiggins.

${ }^{19}$ Nos cálculos supôs-se que cada indivíduo vive até os 100 anos. Foram feitas formulações alternativas, nas quais essa idade foi reduzida em 10 ou 15 anos. As diferenças foram muito pequenas.
} 
1920 e 2000. Como há 4 regiões e 3 níveis de educação, há um total de 972 TIRs. Os valores das TIRs de cada Grupo são apresentados no Apêndice B. Um resumo dos resultados está nas tabelas 9 a 11. A tabela 9 traz as TIRs médias por região. A tabela 10 mostra as TIRs médias por nível educacional e a tabela 11 apresenta os valores médios das TIRs por região e nível de educação.

Tabela 9

Taxas internas de retorno anuais médias por região

(Coortes de 1920 a 2000)

\begin{tabular}{lc}
\hline Região & TIR \\
\hline Sul & 0,0660151 \\
Sudeste & 0,0596813 \\
Nordeste & 0,0798241 \\
Norte + Centro-Oeste & 0,0624591 \\
\hline \multicolumn{2}{l}{ Fonte: Cálculos dos autores. }
\end{tabular}

Tabela 10

Taxas internas de retorno anuais médias por nível de educação

(Coortes de 1920 a 2000)

\begin{tabular}{lc}
\hline Nível de educação & TIR média \\
\hline Nível 1 & 0,0774341 \\
Nível 2 & 0,0625534 \\
Nível 3 & 0,0609972 \\
\hline Fonte: Cálculos dos autores.
\end{tabular}

Tabela 11

Taxas internas de retorno anuais médias por nível de educação e região

(Coortes de 1920 a 2000)

\begin{tabular}{lcccc}
\hline & Nível 1 & Nível 2 & Nível 3 & Média por região \\
\hline Sul & 0,0761081 & 0,0608066 & 0,0611307 & 0,066015 \\
Sudeste & 0,0691526 & 0,0553295 & 0,0545618 & 0,059681 \\
Nordeste & 0,0916431 & 0,0757744 & 0,0720549 & 0,079824 \\
Norte + Centro-Oeste & 0,0728325 & 0,0583031 & 0,0562416 & 0,062459 \\
Média por nível de educação & 0,077434 & 0,062553 & 0,060997 & 0,066995 \\
\hline
\end{tabular}

Fonte: Cálculos dos autores.

A figura 3 mostra os valores dos benefícios, contribuições e VBLs previstos para o Grupo nascido em 1953 na região sudeste, pertencente ao primeiro nível educacional, ou seja, o Grupo 195321. 
Figura 3

Valor dos benefícios, contribuições e benefícios líqüidos por ano - grupo 195321 (em R\$ de setembro/99)

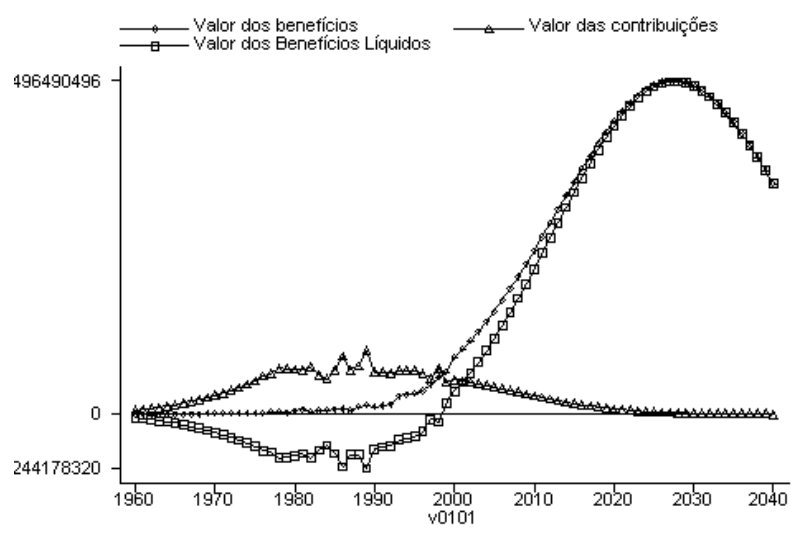

Os resultados encontrados também podem ser apresentados por meio de figuras. A figura 4 mostra as taxas de retorno por nível educacional, para a região nordeste. Na seqüência, a figura 5 apresenta as TIRs por região, para o primeiro nível educacional. ${ }^{20}$

\section{Figura 4}

Taxas internas de retorno por nível de educação - região nordeste

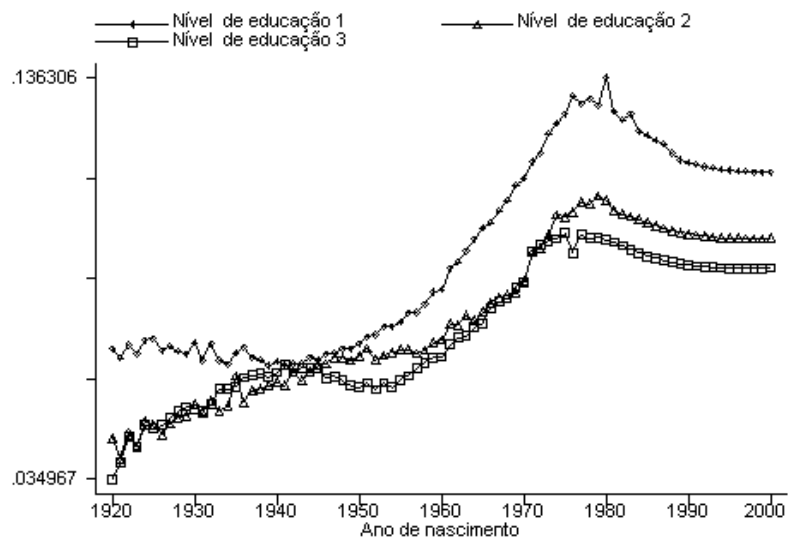

\footnotetext{
${ }^{20}$ Por questão de espaço, não são apresentados as figuras dos outros níveis educacionais e regiões. Estes são bastante semelhantes as figuras 4 e 5 . 
Figura 5

Taxas internas de retorno por ano de nascimento e região - nível educacional 1

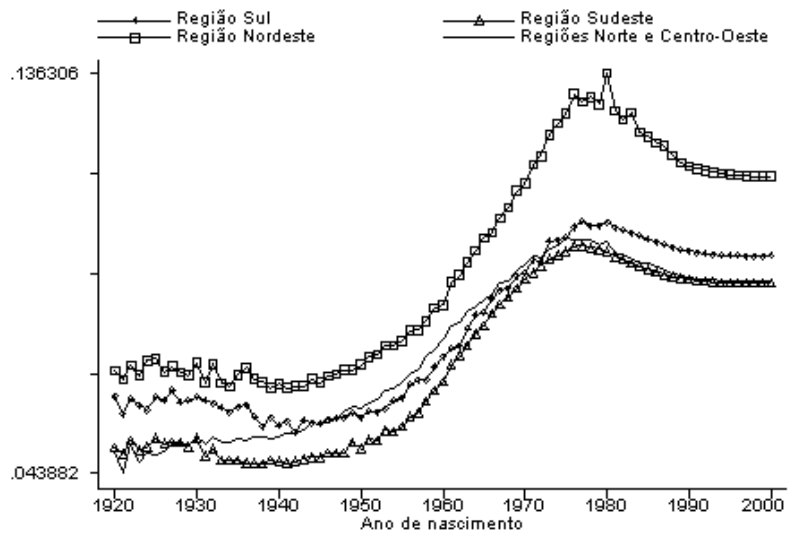

Adicionalmente pode ser estimada uma regressão das taxas internas de retorno de cada Grupo, em função do ano de nascimento e das dummies de região e de educação. Estes novos resultados são apresentados na tabela 12. Na regressão foram omitidas as dummies relativas à região nordeste e ao primeiro nível educacional. Os valores das dummies dos demais níveis de educação são negativos, o que está de acordo com os resultados anteriores. O fato de uma pessoa morar na região sul reduz em $28,5 \%$ sua TIR, comparativamente a um morador do nordeste. Para os níveis de educação, o argumento é análogo: indivíduos do terceiro nível educacional têm taxas de retorno cerca de $22,4 \%$ inferiores àqueles pertencentes ao primeiro nível de educação. Estes dois resultados são uma evidência do caráter distributivo e da progressividade do sistema previdenciário brasileiro. 
Tabela 12

Regressão da taxa interna de retorno em função das variáveis de grupo

\begin{tabular}{lc}
\hline \multicolumn{2}{c}{ Variável dependente: ln (TIR) } \\
\hline Ano de nascimento & 0,1021836 \\
& $(3,81)$ \\
(Ano de nascimento)2 & $-0,0000238$ \\
& $(-3,48)$ \\
Dummy Região sul & $-0,1760662$ \\
& $(-18,59)$ \\
Dummy Região sudeste & $-0,2853179$ \\
& $(-30,13)$ \\
Dummy Região norte+centro-oeste & $-0,236689$ \\
& $(-25,00)$ \\
Dummy Nível de educação 2 & $-0,2050665$ \\
& $(-25,01)$ \\
Dummy Nível de educação 3 & $-0,2238265$ \\
& $(-27,30)$ \\
Constante & $-111,2603$ \\
& $(-4,23)$ \\
\hline N & 972 \\
R2 ajustado & 0,8569 \\
\hline Obs: Regressões estimadas por & \\
MQO. Estatística $t$ entre parênteses &
\end{tabular}

\section{Conclusão}

Os resultados obtidos levam a duas conclusões. A primeira é que há evidências de que o sistema previdenciário brasileiro apresenta características distributivas no sentido correto. A segunda é que, de forma oposta àquela encontrada na literatura internacional, as taxas de retorno não têm apresentado tendência de queda ao longo dos anos. Particularmente, se o padrão de comparação for a previdência dos EUA, é possível afirmar-se que nosso sistema previdenciário proporciona TIRs relativamente elevadas aos seus segurados.

Em cada região, as taxas de retorno dos indivíduos com nível educacional mais baixo são superiores às taxas dos demais níveis. Como indivíduos de nível educacional mais baixo devem ter rendimentos inferiores em relação aos demais, há evidências de que os Grupos mais pobres estão obtendo uma remuneração mais elevada por suas contribuições previdenciárias. Este padrão distributivo se repete de forma similar, analisando-se os resultados por nível educacional. Para todos os níveis educacionais, os retornos obtidos pelos moradores da região nordeste são claramente mais elevados que os das demais regiões, a não ser para algumas coor- 
tes mais antigas do segundo nível educacional. As taxas da região sudeste são, em geral, as mais baixas e as regiões sul e norte/centro-oeste estão em um nível intermediário.

Se considerarmos que a região nordeste apresenta a menor renda per capita do país, então o sistema previdenciário funciona como um mecanismo de transferência de renda das regiões mais ricas para as mais pobres. Dados os diferenciais de taxas encontrados em nossos cálculos, é possível afirmar que há evidências de que nosso sistema previdenciário apresenta progressividade.

A evolução temporal das taxas de retorno também deve ser objeto de atenção. As taxas crescem de forma quase que monotônica no período analisado, até se estabilizarem para as gerações nascidas no início da década de 80. Estes resultados configuram a existência de aspectos distributivos intergeracionais, dado que as coortes mais novas obtêm retornos superiores aos das gerações mais antigas. Como a magnitude das taxas é relativamente elevada (6,7\% ao ano, em média), também pode-se concluir que o sistema previdenciário é uma forma de contrato social vantajosa, particularmente para os grupos mais jovens e mais pobres.

Nas PNADs, não há como diferenciar o tipo de benefício recebido. Desta forma, nos cálculos estão englobadas duas categorias de benefícios. Na primeira, os vínculos com as contribuições passadas são mais fortes, como ocorre, por exemplo, com as aposentadorias por tempo de serviço. Já a segunda categoria compreende os benefícios classificados como previdenciários, mas que têm características claramente assistenciais.

Nesta categoria se incluem, por exemplo, as rendas mensais vitalícias (RMV), depois substituídas pelos benefícios da Lei Orgânica de Assistência Social (LOAS) a previdência rural e, em menor grau, a aposentadoria por idade, nos quais o vínculo contributivo é muito tênue. Como os indivíduos que recebem esses benefícios devem ser os moradores menos educados das regiões mais pobres, suas taxas de retorno devem, em consonância, ser mais elevadas.

No cômputo dos benefícios estão somados todos os valores pagos, tanto a beneficiários do setor privado, quanto do setor público, pois não há nas PNADs informações que permitam separar essas duas categorias. As taxas de retorno calculadas talvez estejam um pouco enviesadas para cima, devido às condições específicas dos funcionários públicos, particularmente aqueles vinculados ao RJU. É razoável inferir que, dada a diferença de regras, existe distribuição intrageracional (dos funcionários do setor privado para os trabalhadores do setor público) não quantificada neste trabalho. Se houvesse como separar os segurados do RGPS, suas TIRs seriam menores. E, por outro lado, as TIRs dos servidores públicos seriam mais altas. 
Nosso sistema previdenciário, tanto para o setor público, quanto para o setor privado, tem gerado a cada ano imensos déficits. Sendo as contribuições inferiores aos benefícios, as taxas de retorno devem ser maiores do que se houvesse equilíbrio entre ambos. A previdência social progressivamente incorporou novos segurados e expandiu o conjunto de benefícios oferecidos. Como destes últimos, vários têm características assistenciais, sua implantação implicou crescimento das despesas de forma mais do que proporcional ao aumento das receitas. Nem o contínuo incremento das alíquotas de contribuição foi capaz de obstaculizar essa tendência.

Os beneficiários dessas políticas devem ter elevadas taxas de retorno, dada a reduzida relação entre suas contribuições e seus benefícios. Este fato pode ser constatado nas taxas obtidas pelos moradores do nordeste e pelos indivíduos com menor grau de instrução. No entanto, tais benefícios representam um papel importante na composição do déficit previdenciário. Este é o ônus que pagamos por ter um sistema previdenciário com características distributivas, inter e intrageracionais, com taxas de retorno mais elevadas para os Grupos mais pobres.

\section{Referências}

Aaron, H. J. (1977). Demographic effects on the equity of social security benefits. In Feldstein, M. S. \& Inman, R., editors, The Economics of Public Services. Macmillan, Londres.

Afonso, L. E. (2003). Um estudo dos aspectos distributivos da previdência social no Brasil. Tese de Doutorado apresentada ao Departamento de Economia da Faculdade de Economia, Administração e Contabilidade da USP.

Anderson, M., Yamagata, H., Tuljapurkar, S., \& Lee, R. (2001). Stochastic rates of return for social security under various policy scenarios. Trabalho apresentado no Third Annual Joint Conference for the Retirement Research Consortium "Making Hard Choices About Retirement". Washington, DC.

Barros, R. P. \& Carvalho, M. (2003). Desafios para a política social brasileira. Rio de Janeiro, Ipea, Texto para Discussão 895.

Beach, W. W. \& Davis, G. G. (1998). Social security's rate of return. The Heritage Center for Data Analysis CDA98-01.

Boskin, M. J., Kotlikoff, L. J., Puffert, D. J., \& Shoven, J. B. (1987). Social security: A financial appraisal across and within generations. National Tax Journal, 40(1):19-34. 
Boskin, M. J. \& Puffert, D. J. (1987). The financial impact of social social security by cohort under alternative financing assumptions. NBER Working Paper 2225.

Bosworth, B. \& Burtless, G. (2000). The effects of social security reform on saving, investment, and the level and distribution of worker well-being. Center for Retirement Research at Boston College. WP 2000-02.

Bosworth, B. \& Burtless, G. (2002). Economic and distributional effects of the proposals of president Bush's social security commission. Trabalho apresentado no Fourth Annual Joint Conference for the Retirement Research Consortium. Directions for social security reform. Second Draft. Washington, DC.

Bosworth, B., Burtless, G., \& Keys, B. (2003). Implications of the Bush commission pension reforms for married couples. Center for Retirement Research at Boston College. Working Paper 2003-03.

Bosworth, B., Burtless, G., \& Steuerle, C. E. (1999). Lifetime earnings patterns, the distribution of future social security benefits, and the impact of pension reform. Center for Retirement Research at Boston College. Working Paper 1999-06.

Buchanan, J. M. (1968). Social insurance in a growing economy: A proposal for radical reform. National Tax Journal, 21(4):386-95.

Burkhauser, R. V. \& Warlick, J. L. (1981). Disentangling the annuity from the redistributive aspects of social security in the United States. Review of Income and Wealth, 27:401-21.

Conde-Ruiz, J. I. \& Profeta, P. (2003). What social security: Beveridgean or Bismarckian? Fundación de Estudios de Economía Aplicada. Documento de trabajo 2003-16.

Coronado, J. L., Fullerton, D., \& Glass, T. (2000a). Long run effects of social security reform proposals on lifetime progressivity. NBER Working Paper 7568.

Coronado, J. L., Fullerton, D., \& Glass, T. (2000b). The progressivity of social security. NBER Working Paper 7520.

Diamond, P. A. (1977). A framework for social security analysis. Journal of Public Economics, 8(3):275-98.

Duggan, J. E., Gillingham, R., \& Greenlees, J. S. (1993). Returns paid to early social security cohorts. Contemporary Policy Issues, 11:1-13. 
Duggan, J. E., Gillingham, R., \& Greenlees, J. S. (1995). Progressive returns to social security? An answer from social security records. Research Paper 9501. Office of Economic Policy. U. S. Department of the Treasury. Washington, DC.

Feldstein, M. (1985). The optimal level of social security benefits. The Quarterly Journal of Economics, 100(2):303-320.

Feldstein, M. \& Liebman, J. (2000). The distributional effects of an investmentbased social security system. NBER Working Paper 7492.

Fernandes, F. (1994). Sistema previdenciário e desigualdades inter e intrageracionais no Brasil: O papel da dinâmica demográfica. Previdência em Dados, $9(4): 5-36$.

Foguel, M. N. (1998). Uma avaliação dos efeitos do salário mínimo sobre o mercado de trabalho no Brasil. Rio de Janeiro, Ipea, Texto para Discussão 564.

Garrett, D. M. (1995). The effects of differential mortality rates on the progressivity of social security. Economic Inquiry, 23:457-75.

Giambiagi, F., Mendonça, J. L. O., Beltrão, K. I., \& Ardeo, V. L. (2004). Diagnóstico da previdência social no Brasil: O que foi feito e o que falta reformar? Pesquisa e Planejamento Econômico, 34(3).

Gil, J. \& Lopez-Casasnovas, G. (1997). Life-time redistribution effects of the spanish public pension system. Department of Economics and Statistics, Universitat Pompeu Fabra. Working Paper 242.

Gosling, A., Machin, S., \& Meghir, C. (1999). The changing distribution of male wages in the UK. The Institute for Fiscal Studies. Working Paper Series W98/9.

Gustman, A. L. \& Steinmeier, T. L. (2001). How effective is redistribution under the social security benefit formula? Journal of Public Economics, 82(1):1-28.

Hoffmann, R. (2003). A contribuição das aposentadorias e do rendimento agrícola para a desigualdade do rendimento domiciliar per capita do Brasil. In Benecke, D. W. \& Nascimento, R. (orgs), Política social preventiva: desafio para o Brasil. Konrad-Adenauer-Stiftung: Rio de Janeiro.

Hubbard, R. G. \& Judd, K. L. (1987). Social security and individual welfare: Precautionary saving, borrowing constraints, and the payroll tax. American Economic Review, 77(4):630-646. 
Hurd, M. D. \& Shoven, J. B. (1983). The distributional impact of social security. NBER Working Paper 1155.

Leimer, D. R. (1999). Lifetime redistribution under the social security: A literature synopsis. Social Security Bulletin, 62(2):1-9.

Leimer, D. R. \& Petri, P. A. (1981). Cohort-specific effects of social security policy. National Tax Journal, 34(1):9-20.

Liebman, J. B. (2001). Redistribution in the current U.S. social security system. NBER Working Paper 8625.

Menezes-Filho, N. A., Fernandes, R., \& Picchetti, P. (2000). A evolução da distribuição de salários no Brasil: Fatos estilizados para as décadas de 80 e 90 . In Henriques, R. (org.). Desigualdade e pobreza no Brasil. Ipea: Rio de Janeiro.

MPAS (1999a). Anuário estatístico da previdência social. Versão eletrônica disponível para download no site www.mps.gov.br.

MPAS (1999b). Informe de previdência social. 11(8).

MPAS (2000). Anuário estatístico da previdência social. Versão eletrônica disponível no site www.mps.gov.br.

Myers, R. J. \& Schobel, B. D. (1992). An updated money's-worth analysis of social security retirement benefits. Transactions of Society of Actuaries, 44:247-87.

Saboia, J. L. M. (1984). Evolução histórica do salário mínimo no Brasil: Fixação, valor real e diferenciação regional. PNPE. Série Fac-Símile 15.

Samuelson, P. (1958). An exact consumption-loan model of interest with or without the social contrivance of money. Journal of Political Economy, 66(6):467-82.

Schwarzer, H. (1999). Perfis da remuneração média do trabalho por idade, posição na ocupação, gênero e escolaridade no Brasil, 1997, e sua relação com a regra de cálculo do salário de benefício no regime geral de previdência social. Conjuntura Social, 10(4):101-21.

Silva, E. R. A. \& Delgado, D. (2000). Condições de efetividade e universalização da previdência rural. In Delgado, D. \& Cardoso Júnior, J. C. (orgs). A universalização de direitos sociais no Brasil: A previdência rural nos anos 90. Ipea: Rio de Janeiro. 
Sinn, H. W. (1999). The crisis in Germany' s pension insurance system and how it can be resolved. NBER Working Paper 7304.

Veall, M. R. (1986). Public pensions as optimal social contracts. Journal of Public Economics, 31(2):237-51.

World Bank (1995). Brazil social insurance and private pensions. Report 12336BR. Country Operations Division, Country Department I, Latin America and the Caribbean Region. 


\section{Apêndice A}

\section{Mudanças da Legislação Previdenciária no Período 1976-1999}

Para os empregados comuns, por todo o período 1976-1979, as regras de contribuição não se alteram, sendo dadas pelas Leis 4863, de 1965 e 5890, de 1973. A primeira definiu as alíquotas de contribuição dos empregados e empregadores, respectivamente, como $8 \%$ e 13,5\% do salário-de-contribuição. A segunda limitou o salário-de-contribuição em 20 vezes o maior salário mínimo vigente no país. Elevou também a alíquota de contribuição dos empregadores para 15,9\%, sendo de 8,0\% a alíquota básica, acrescida de 4,3\% para o salário-família, 2,4\% para a previdência rural e 1,2\% devido ao $13^{\circ}$ salário. Para os empregados domésticos, a Lei 5859 de dezembro de 1972 fixou a alíquota de contribuição do empregador em 8\% do salário mínimo da região. Para cada ano, até 1984, quando o salário mínimo foi unificado nacionalmente, devido aos limites impostos para o salário-de-contribuição, é necessário comparar o salário mínimo dos trabalhadores comuns com o maior salário mínimo em vigência no país. E para os empregados domésticos, a comparação deve ser feita com o salário mínimo da região. Os estados que compõem cada região e os valores do salário mínimo (por ano e estado) podem ser encontrados em Saboia (1984) e Foguel (1998).

A primeira mudança para os trabalhadores comuns ocorreu com o Decreto-Lei 1910, de dezembro de 1981. Houve um aumento na alíquota dos empregadores, para $18,2 \%$. A alíquota básica foi majorada para $10 \%$ e a parcela do saláriofamília foi reduzida para 4,0\% (compensada pela inclusão de uma alíquota de 0,3\% destinada ao salário-maternidade, de acordo com a Lei 6950, do mesmo ano). A parcela relativa à previdência rural manteve-se em $2,4 \%$ e a alíquota destinada ao $13^{\circ}$ salário aumentou para 1,5\%. As alíquotas dos empregados passaram a ser diferenciadas, conforme a faixa de salário $(Y)$ do trabalhador, tendo como base múltiplos do salário mínimo regional (SMR), como pode ser visto na tabela A.1. 
Tabela A.1

Alíquotas de contribuição dos empregados (Decreto-Lei 1910/81)

\begin{tabular}{lc}
\hline Faixa salarial & Alíquota (\%) \\
\hline $0 \leq \mathrm{Y} \leq 3 \mathrm{SMR}$ & 8,50 \\
$3 \mathrm{SMR}<\mathrm{Y} \leq 5 \mathrm{SMR}$ & 8,75 \\
$5 \mathrm{SMR}<\mathrm{Y} \leq 10 \mathrm{SMR}$ & 9,00 \\
$10 \mathrm{SMR}<\mathrm{Y} \leq 15 \mathrm{SMR}$ & 9,50 \\
$15 \mathrm{SMR}<\mathrm{Y} \leq 20 \mathrm{SMR}$ & 10,00 \\
\hline
\end{tabular}

Em 1984 o salário mínimo foi unificado. Deixou de existir o salário mínimo regional (SMR) e os limites de contribuição passam a ser expressos em múltiplos do salário mínimo (SM). Em agosto de 1987, o Decreto-Lei 2351 acrescentou dois termos ao conjunto de referências salariais. O primeiro é o Piso Nacional de Salários (PNS), cujo valor era de CZ\$1.970,00. O segundo é o Salário Mínimo de Referência (SMR), nova designação do salário mínimo, valendo $\mathrm{CZ} \$ 1.969,92$. Com essa alteração, o salário-de-contribuição do INSS passou a ter como teto vinte vezes o valor vigente do SMR.

Esta regra foi efêmera. A Lei 7787 de junho de 1989 unificou (e elevou de 18,2\% para 20\%) a alíquota das empresas. As empresas do setor financeiro tiveram seu encargo elevado em 2,5 pontos percentuais, o que aumentou sua contribuição para $22,5 \%$. A alíquota do empregador doméstico foi elevada para $12 \%$ do salário-decontribuição do empregado. Para os trabalhadores, incluindo-se os empregados domésticos, reduziu-se o número de faixas, conforme mostrado na tabela A.2.

Tabela A.2

Alíquotas de contribuição dos empregados (Lei 7787/89)

\begin{tabular}{lc}
\hline Faixa salarial & Alíquota (\%) \\
\hline $0 \leq \mathrm{Y} \leq 3 \mathrm{SM}$ & 8,00 \\
$3 \mathrm{SM}<\mathrm{Y} \leq 5 \mathrm{SM}$ & 9,00 \\
$5 \mathrm{SM}<\mathrm{Y} \leq 10 \mathrm{SM}$ & 10,00 \\
\hline
\end{tabular}

Em abril de 1995, a faixa mais alta de renda teve sua alíquota de contribuição elevada de $10 \%$ para $11 \%$ pela Lei 9032 , conforme mostrado na tabela A.3. Este aumento entrou em vigor em agosto do mesmo ano. Nesta data o salário mínimo era de $\mathrm{R} \$ 100,00$.

Tabela A.3

Alíquotas de contribuição dos empregados (Lei 9032/95) (valores em R $\$$ correntes)

\begin{tabular}{lc}
\hline Faixa salarial & Alíquota $(\%)$ \\
\hline $0 \leq \mathrm{Y} \leq 249,80$ & 8,00 \\
$249,80<\mathrm{Y} \leq 416,33$ & 9,00 \\
$416,33<\mathrm{Y} \leq 832,66$ & 11,00 \\
\hline
\end{tabular}


Em outubro de 1996, a Lei 9311 criou a CPMF, o que implicou duas mudanças para a previdência. Os benefícios com valor inferior a dez salários mínimos foram majorados para que os beneficiários não fossem prejudicados. As alíquotas de contribuição incidentes, até o limite de três salários mínimos, foram reduzidas, para que os segurados da previdência não tivessem aumentado o valor de suas contribuições. Durante 1997, houve três regras de contribuição para os empregados, como pode ser visto nas tabelas A.4 a A.6. A primeira regra tem vigência de janeiro a abril. A segunda regra vale apenas para mês de maio. E a terceira regra vale de junho até o final do ano.

Tabela A.4

Alíquotas de contribuição dos empregados (Lei 9311/96)

(valores em $\mathrm{R} \$$ correntes)

\begin{tabular}{lc}
\hline Faixa salarial & Alíquota (\%) \\
\hline $0 \leq \mathrm{Y} \leq 287,27$ & 7,82 \\
$287,27<\mathrm{Y} \leq 336,00$ & 8,82 \\
$336,00<\mathrm{Y} \leq 478,78$ & 9,00 \\
$478,78<\mathrm{Y} \leq 957,56$ & 11,00 \\
\hline
\end{tabular}

Tabela A.5

Alíquotas de contribuição dos empregados (Lei 9311/96)

(valores em $\mathrm{R} \$$ correntes)

\begin{tabular}{lc}
\hline Faixa salarial & Alíquota $(\%)$ \\
\hline $0 \leq \mathrm{Y} \leq 287,27$ & 7,82 \\
$287,27<\mathrm{Y} \leq 360,00$ & 8,82 \\
$336,00<\mathrm{Y} \leq 478,78$ & 9,00 \\
$478,78<\mathrm{Y} \leq 957,56$ & 11,00 \\
\hline
\end{tabular}

Tabela A.6

Alíquotas de contribuição dos empregados (Lei 9311/96)

(valores em $\mathrm{R} \$$ correntes)

\begin{tabular}{lc}
\hline Faixa salarial & Alíquota (\%) \\
\hline $0 \leq \mathrm{Y} \leq 309,56$ & 7,82 \\
$309,56<\mathrm{Y} \leq 360,00$ & 8,82 \\
$360,00<\mathrm{Y} \leq 515,93$ & 9,00 \\
$515,93<\mathrm{Y} \leq 1031,87$ & 11,00 \\
\hline
\end{tabular}

Em 1998, repete-se a situação do ano anterior, com três regras, cada uma válida, respectivamente, por quatro, um e sete meses. Os valores para os dois últimos casos (pois o primeiro é a última regra de 1997) encontram-se nas tabelas A.7 e A.8. A base para ambas é a Lei 9539 de dezembro de 1997. 
Tabela A.7

Alíquotas de contribuição dos empregados (Lei 9539/97)

(valores em $\mathrm{R} \$$ correntes)

\begin{tabular}{lc}
\hline Faixa salarial & Alíquota (\%) \\
\hline $0 \leq \mathrm{Y} \leq 309,56$ & 7,82 \\
$309,56<\mathrm{Y} \leq 390,00$ & 8,82 \\
$390,00<\mathrm{Y} \leq 515,93$ & 9,00 \\
$515,93<\mathrm{Y} \leq 1031,87$ & 11,00 \\
\hline
\end{tabular}

Tabela A.8

Alíquotas de contribuição dos empregados (Lei 9539/97)

(valores em $\mathrm{R} \$$ correntes)

\begin{tabular}{lc}
\hline Faixa salarial & Alíquota $(\%)$ \\
\hline $0 \leq \mathrm{Y} \leq 324,45$ & 7,82 \\
$324,45<\mathrm{Y} \leq 390,00$ & 8,82 \\
$390,00<\mathrm{Y} \leq 540,75$ & 9,00 \\
$540,75<\mathrm{Y} \leq 1081,50$ & 11,00 \\
\hline
\end{tabular}

O ano de 1999 também é regido por duas regras, apresentadas nas tabelas A.9 e A.10. A primeira é dada pela Emenda Constitucional 20, de dezembro de 1998. A segunda é definida pela Emenda Constitucional 21, de março de 1999. Ambas são mostradas a seguir. As alíquotas e valores da tabela A.10 entram em vigência a partir de 17 de junho.

Tabela A.9

Alíquotas de contribuição dos empregados (Emenda Constitucional 20/1998)

(valores em $\mathrm{R} \$$ correntes)

\begin{tabular}{lc}
\hline Faixa salarial & Alíquota $(\%)$ \\
\hline $0 \leq \mathrm{Y} \leq 360,00$ & 7,82 \\
$360,00<\mathrm{Y} \leq 390,00$ & 8,82 \\
$390,00<\mathrm{Y} \leq 600,00$ & 9,00 \\
$600,00<\mathrm{Y} \leq 1200,00$ & 11,00 \\
\hline
\end{tabular}

Tabela A.10

Alíquotas de contribuição dos empregados (Emenda Constitucional 21/1999)

(valores em $\mathrm{R} \$$ correntes)

\begin{tabular}{lc}
\hline Faixa salarial & Alíquota $(\%)$ \\
\hline $0 \leq \mathrm{Y} \leq 376,60$ & 7,65 \\
$376,60<\mathrm{Y} \leq 408,00$ & 8,65 \\
$408,00<\mathrm{Y} \leq 627,66$ & 9,00 \\
$627,66<\mathrm{Y} \leq 1255,32$ & 11,00 \\
\hline
\end{tabular}


Em janeiro de 1999, a Lei 9783 mudou a regra de contribuição dos funcionários públicos estatutários. Sua alíquota de contribuição passou a ser diferenciada por faixa salarial, como pode ser visto na tabela A.11.

Tabela A.11

Alíquotas de contribuição dos estatutários (Lei 9783/1999)

(valores em $\mathrm{R} \$$ correntes)

\begin{tabular}{lc}
\hline Faixa salarial & Alíquota (\%) \\
\hline $0 \leq \mathrm{Y} \leq 1200,00$ & 11,00 \\
$1200,00<\mathrm{Y} \leq 2500,00$ & 12,00 \\
$\mathrm{Y}>2500,00$ & 25,00 \\
\hline
\end{tabular}




\title{
Apêndice $B$
}

\section{Taxas Internas de Retorno (TIR) por Grupo}

\author{
Tabela B.1 \\ Taxas internas de retorno anuais por Grupo - Coortes de 1920 a 2000
}

\begin{tabular}{|c|c|c|c|c|c|c|c|c|c|c|c|c|}
\hline \multirow{4}{*}{$\begin{array}{c}\text { Ano de } \\
\text { nasci- } \\
\text { mento }\end{array}$} & \multicolumn{12}{|c|}{ Região e Nível de educação } \\
\hline & \multicolumn{3}{|c|}{ Sul } & \multicolumn{3}{|c|}{ Sudeste } & \multicolumn{3}{|c|}{ Nordeste } & \multicolumn{3}{|c|}{ Norte + Centro-Oeste } \\
\hline & el & Nível & Nível & ível & Nível & Nível & Nível & Nível & Nível & Nível & Nível & Nível \\
\hline & 1 & 2 & 3 & 1 & 2 & 3 & 1 & 2 & 3 & 1 & 2 & 3 \\
\hline 1920 & 0,061667 & 0,044198 & 0,03752 & 0,049824 & 0,03826 &, 034378 & 0,067674 & 0,045247 & 0,034967 & 0,04887 & 0,037962 & 0,03428 \\
\hline 1921 & 57601 & ,04616 & 0,039039 & 0,048411 & 0,038533 & 033335 & 0,065464 & 0,040047 & 0,039057 & 043882 & 0,036926 &, 031909 \\
\hline 1922 & 60983 & 0,05185 & 0,04083 & 0,051345 & 0,037687 &, 035723 & 68794 & 0,046755 & 0,045569 &, 050477 & 0,036295 & 0,037962 \\
\hline 1923 & ,05954 & 049464 & 0,041034 & 0,049176 & 0,039251 &, 038362 & 0,066501 & 0,043235 & 0,043118 & 0,046679 & 0,035805 & 0,0335 \\
\hline 1924 & 58459 & 047156 & 0,04285 & & 0,041494 & ,038041 & 069863 & 0,049623 & 0,048609 & 048492 & 0,038646 & 405 \\
\hline 1925 & & 0,048112 & 0,04 & 0 & 0,044265 & 0,039785 & 0,070 & 0,048618 & 0,047 &, 048242 & 0,040913 & 0,040 \\
\hline 1926 & 8 & 0,051 & 0,045 & 0,050 & 0,044058 & 0,040183 & 0,067366 & 0,04616 & 0,048547 & ,049096 & 0,038866 & 0,041 \\
\hline 1927 & 063221 & 0,052346 & 0,048228 & 0,050936 & 0,04273 &, 041273 & 0,068515 & 0,048873 & 334 & 050557 & 0,042116 & 0,044 \\
\hline 1928 & 68 & 0,051761 & 0,04 & 0,05 & 0,042298 & 0,04133 & 0,067143 & 0,050506 & 24 & 050449 & 0,04 & \\
\hline 1929 & & ,04992 & 442 & & 0,044713 & 0,043137 & & 0,0 & 12 & 8 & & \\
\hline 1930 & 09 & 0,051937 & 0,0 & 43 & 0,044954 & 0,043091 & 0,06 & 0,053674 & 0,05 & 0,0 & 0,04 & 0,0 \\
\hline 1931 & 0,060532 & 0,053669 & 0,052234 & 0,047815 & 0,042362 & 0,043476 & 0,064813 & 0,051667 & 0,052085 &, 050386 & 0,045084 & 0,048 \\
\hline 1932 & 0,059937 & 0,054175 & 0,05 & 68 & 0,04385 & 0,045723 & 0,069134 & 0,054865 & 888 &, 052084 & 0,04649 & 0.05 \\
\hline 1933 & & 053765 & 061 & & 0,04448 & 0,04744 & 064 & 059 & & 050917 & 0,045 & \\
\hline 1934 & & 0,055 & & & 5401 & 0,047264 & & & & & & \\
\hline 1935 & & 056019 & 7 & & 909 & 0,048264 & 0,06 & 0,0 & & & 0,0 & \\
\hline 1936 & 76 & 052112 & 98 & 1 & 8264 & 9065 & 0,0 & 0,0 & & 74 & 0,0 & 0 \\
\hline 1937 & 16 & 0,054224 & 71 & 25 & 0,046932 & 0,049098 & 0,06 & 32 & & 67 & 0,0 & ( \\
\hline 1938 & 01 & ,05461 & 24 & 16 & 7323 & 0,048452 & 0 , & 15 & 52 & 73 & 0,0 & 0,0 \\
\hline 1939 & 0,056852 & 0,053916 & 709 & 0,04 & 0,047128 & 049795 & 0,06 & 0,0 & 74 & 34 & 0,05 & 14 \\
\hline 1940 & 48 & 053088 & 0,05 & 0,04 & 0,047641 & 0,0486 & 0,064548 & 0,05 & 825 &, 05216 & 0,05 & 62 \\
\hline 1941 & 0,05 & 0,053254 & 0,0 & 33 & 0,047586 & ,049643 & 0,06 & 564 & 344 &, 053256 & 0,05 &, 0 \\
\hline 1942 & 0,05 & 0,05439 & 82 & & 0,047486 &, 049226 & 0,0639 & 226 & & 37 & 0,05 & 8 \\
\hline & & 1 & & & & & & & & & & \\
\hline & & 0 , & & & & & 0,0 & & & & & \\
\hline & & 5 & & & & 5 & 0,0 & & & 61 & 0,0 & \\
\hline 1946 & 0 & 0,055 & 19 & & 188 & 0,04871 & 0,06 & 02 & & 8 & & \\
\hline 1947 & & 0,05 & & & 492 & 0,046878 & 0,06 & & & 51 & 0,0 & \\
\hline 1948 & 352 & 0,055012 & 81 & & 7368 & 0,045594 & 0,06 & 0,0 & 78 & 71 & 0,0 & 0 \\
\hline 1949 & 56 & 0,054937 & 67 & 13 & 6843 & 0,047146 & 0,06 & 0,0 & 52 & 29 & 0,0 & \\
\hline 1950 & 32 & 053183 & 0,0 & 29 & 0,047101 & 0,046788 & 0,06905 & 506 & 85 & 41 & 0,0 & 0, \\
\hline 1951 & 57 & 054262 & 88 & 79 & 0,045941 & 0,045853 & 0,07 & 33 & & 77 & 0,0 & \\
\hline 1952 & & 0,053415 & 97 & & 0,044692 & 0,044756 & 0,07 & 99 & & 31 & 0,0 & 5 \\
\hline & & & & & & & & & & & & \\
\hline & & 0 & & & 8 & & & & & & & \\
\hline & & & & & & & & & & & & \\
\hline 19 & & & & & & & & & & & & \\
\hline 19 & & & & & & 5 & & & & & & \\
\hline 1958 & & 0,048107 & 45 & & 0,045612 & 0,049245 & ,079 & 48 & & 65 & 0,0 & 7 \\
\hline 1959 & & 0,048232 & & & 0,046136 & 0,05042 & 0,082 & 361 & 46 & 535 & 0,05 & 0,0 \\
\hline 1960 & 05 & 0,04834 & 0,05 & 41 & 0,046347 & ,05139 & 0,082798 & 116 & 0,06 & 0,075 & 0,05 & 0,0 \\
\hline 1961 & 677 & 049339 & 949 & 908 & 0,048936 & 0,055202 & 0,088078 &, 073976 & 99 & 0,07 & 0,05 & 0,05 \\
\hline 1962 & 3 & 0,049203 & & 9 & 04796 &, 054259 & 6 & 351 & 13 & 61 & 0,0 & \\
\hline 1963 & & 06 & & & 046 & 904 & 0,0 & 289 & 0,0 & 59 & 0,0 & 0,0 \\
\hline 1964 & 71 & 0,050 & & & 349 & 88 & & 79 & & 41 & & \\
\hline 1965 & 01 & 092 & $0,0 \epsilon$ & & 11 & 5198 & 0,09 & 65 & & & & \\
\hline & & & & & 19 & & & & & & & \\
\hline 1967 & & 0,056141 & & & 116 & 59515 & & & & & & \\
\hline & & 0,05628 & & & 639 & & & & & & & \\
\hline & & 056186 & 812 & & 56547 & 0,062631 & 01 & 13 & & & 0,0 & 0 \\
\hline 1970 & & 57618 & & & 0,056542 & 06207 & 110813 & 49 & 91 & 24 & 0,06 & 0,0 \\
\hline 1971 & 3094 & 062054 & 0,069713 & 90287 & 060536 & 0,065654 & 115136 & 0,092183 & 0,092433 & 27 & 0,064398 & 067 \\
\hline 1972 & 2538 & 562 & 069235 & & 9 & 9 & & & & & & \\
\hline & & 63927 & & 3434 & 0,061033 & 0,0668 & 0,122089 & 0,096651 & 0,09 & 0,095801 & 0,067731 & 0,06 \\
\hline 1974 & 34 & 0,066889 & 0,070182 & 0,094239 & 0,063259 & 0,066642 & 0,124 & 0,10 & 0,0 & 0,09 & 0,06 & 0,0 \\
\hline 1975 & D,090320 & 0,067965 & 0,073006 & 0,09522 & 0,065194 & 0,064514 & 0,127024 & 0,101099 & 0,096991 & 0,098168 & 0,070469 & 0,068479 \\
\hline
\end{tabular}




\begin{tabular}{|c|c|c|c|c|c|c|c|c|c|c|c|c|}
\hline \multirow{4}{*}{$\begin{array}{c}\text { Ano de } \\
\text { nasci- } \\
\text { mento }\end{array}$} & \multicolumn{12}{|c|}{ Região e Nível de educação } \\
\hline & \multicolumn{3}{|c|}{ Sul } & \multicolumn{3}{|c|}{ Sudeste } & \multicolumn{3}{|c|}{ Nordeste } & \multicolumn{3}{|c|}{ Norte + Centro-Oeste } \\
\hline & Nível & Nível & Nível & Nível & Nível & Nível & Nível & Nível & Nível & Nível & Nível & Nível \\
\hline & 1 & 2 & 3 & 1 & 2 & 3 & 1 & 2 & 3 & 1 & 2 & 3 \\
\hline 1976 & 0,100766 & 0,07007 & 0,070514 & 0,096375 & 0,067479 & 0,067577 & 0,131638 & 0,102348 & 0,09201 & 0,097739 & 0,067719 & 0,068606 \\
\hline 1977 & 0,102105 & 0,071995 & 0,073623 & 0,096429 & 0,069146 & 0,067086 & 0,129762 & 0,104806 & 0,096659 & 0,098023 & 0,07169 & 0,068949 \\
\hline 1978 & 0,100999 & 0,072828 & 0,073612 & 0,096081 & 0,070188 & 0,067409 & 0,130859 & 0,104433 & 0,095827 & 0,097664 & 0,073644 & 0,068521 \\
\hline 1979 & 0,10103 & 0,073591 & 0,073746 & 0,095585 & 0,071842 & 0,067585 & 0,129148 & 0,106477 & 0,095945 & 0,096606 & 0,073708 & 0,06892 \\
\hline 1980 & 0,101864 & 0,075903 & 0,074148 & 0,095062 & 0,072737 & 0,067793 & 0,136306 & 0,105358 & 0,095287 & 0,097564 & 0,074001 & 0,068787 \\
\hline 1981 & 0,100624 & 0,07757 & 0,074057 & 0,093962 & 0,073362 & 0,067884 & 0,127681 & 0,102763 & 0,094775 & 0,094683 & 0,074394 & 0,068649 \\
\hline 1982 & 0,099957 & 0,078677 & 0,073796 & 0,093278 & 0,073553 & 0,067572 & 0,125556 & 0,10174 & 0,093858 & 0,094333 & 0,074859 & 0,068268 \\
\hline 1983 & 0,099508 & 0,079788 & 0,073524 & 0,092504 & 0,074264 & 0,067216 & 0,12717 & 0,101148 & 0,092853 & 0,09313 & 0,074743 & 0,067771 \\
\hline 1984 & 0,098775 & 0,080265 & 0,073048 & 0,091777 & 0,074205 & 0,066787 & 0,122754 & 0,100547 & 0,092033 & 0,092442 & 0,074894 & 0,067305 \\
\hline 1985 & 0,097928 & 0,080267 & 0,072581 & 0,091098 & 0,073891 & 0,066385 & 0,121621 & 0,099692 & 0,091277 & 0,092272 & 0,074451 & 0,066897 \\
\hline 1986 & 0,097282 & 0,079808 & 0,072179 & 0,090391 & 0,073484 & 0,066048 & 0,120334 & 0,098917 & 0,090628 & 0,091382 & 0,073949 & 0,066555 \\
\hline 1987 & 0,096679 & 0,079375 & 0,071847 & 0,089863 & 0,073097 & 0,065774 & 0,119548 & 0,098247 & 0,090079 & 0,090705 & 0,073626 & 0,066277 \\
\hline 1988 & 0,096075 & 0,079053 & 0,071577 & 0,089387 & 0,07285 & 0,065556 & 0,117303 & 0,097679 & 0,089618 & 0,089922 & 0,073373 & 0,066054 \\
\hline 1989 & 0,095552 & 0,078777 & 0,071363 & 0,088995 & 0,072636 & 0,065386 & 0,115546 & 0,097203 & 0,089236 & 0,089609 & 0,073144 & 0,065881 \\
\hline 1990 & 0,095174 & 0,078556 & 0,071198 & 0,088684 & 0,072462 & 0,065259 & 0,114778 & 0,096807 & 0,088923 & 0,089221 & 0,072966 & 0,06 \\
\hline 1991 & 0,094867 & 0,078386 & 0,071075 & 0,088435 & 0,072331 & 0,06517 & 0,114245 & 0,096483 & 0,088672 & 0,088967 & 0,072833 & 0,065659 \\
\hline 1992 & 0,09462 & 0,078259 & 0,07099 & 0,08824 & 0,072239 & 0,065113 & 0,113801 & 0,096223 & 0,088475 & 0,088768 & 0,072738 & 0,0656 \\
\hline 1993 & 0,094427 & 0,07817 & 0,070937 & 0,088092 & 0,072181 & 0,065085 & 0,113435 & 0,096018 & 0,088326 & 0,088617 & 0,072677 & 0,065571 \\
\hline 1994 & 0,094282 & 0,078115 & 0,070913 & 0,087986 & 0,072152 & 0,065082 & 0,113139 & 0,095862 & 0,088219 & 0,088507 & 0,072646 & 0,065566 \\
\hline 1995 & 0,094179 & 0,07809 & 0,070913 & 0,087916 & 0,072148 & 0,065101 & 0,112903 & 0,09575 & 0,088148 & 0,088435 & 0,07264 & 0,065583 \\
\hline 1996 & 0,094112 & 0,078089 & 0,070934 & 0,087878 & 0,072166 & 0,065138 & 0,112722 & 0,095675 & 0,088108 & 0,088395 & 0,072657 & 0,065618 \\
\hline 1997 & 0,094077 & 0,07811 & 0,070974 & 0,087867 & 0,072203 & 0,06519 & 0,112589 & 0,095633 & 0,088097 & 0,088382 & 0,072693 & 0,06567 \\
\hline 1998 & 0,094068 & 0,07815 & 0,07103 & 0,08788 & 0,072256 & 0,065256 & 0,112496 & 0,095619 & 0,088109 & 0,088393 & 0,072744 & 0,065735 \\
\hline 1999 & 0,094084 & 0,078206 & 0,071098 & 0,087914 & 0,072322 & 0,065332 & 0,11244 & 0,09563 & 0,088142 & 0,088425 & 0,07281 & 0,065811 \\
\hline 2000 & 0,09412 & 0,078275 & 0,071178 & 0,087965 & 0,0724 & 0,065419 & 0,112415 & 0,095661 & 0,088192 & 0,088475 & 0,072887 & 0,065897 \\
\hline
\end{tabular}

Fonte: Cálculos dos autores. 